\title{
Isothermal Ageing of SnAgCu Solder Alloys: Three-Dimensional Morphometry Analysis of Microstructural Evolution and Its Effects on Mechanical Response
}

\author{
MILAD MALEKI, ${ }^{1}$ JOËL CUGNONI, ${ }^{1,2}$ and JOHN BOTSIS ${ }^{1}$ \\ 1.-Laboratoire de Mécanique Appliquée et d'analyse de Fiabilité (LMAF), Ecole Polytechnique \\ Fédérale de Lausanne (EPFL), 1015 Lausanne, Switzerland. 2.—e-mail: joel.cugnoni@epfl.ch
}

Due to the high homologous temperature and fast cooling rates, the microstructures of $\mathrm{SnAgCu}$ (SAC) solders are in a meta-stable state in most applications, which is the cause of significant microstructural evolution and continuous variation in the mechanical behavior of the joints during service. The link between microstructures evolution and deformation behavior of $\mathrm{Sn}-4.0 \mathrm{Ag}-0.5 \mathrm{Cu}$ solder during isothermal ageing is investigated. The evolution of the microstructures in SAC solders are visualized at different scales in 3D by using a combination of synchrotron x-ray and focused ion beam/scanning electron microscopy tomography techniques at different states of ageing. The results show that, although the grain structure, morphology of dendrites, and overall volume fraction of intermetallics remain almost constant during ageing, considerable coarsening occurs in the $\mathrm{Ag}_{3} \mathrm{Sn}$ and $\mathrm{Cu}_{6} \mathrm{Sn}_{5}$ phases to lower the interfacial energy. The change in the morphometrics of sub-micron intermetallics is quantified by $3 \mathrm{D}$ statistical analyses and the kinetic of coarsening is discussed. The mechanical behavior of SAC solders is experimentally measured and shows a continuous reduction in the yield resistance of solder during ageing. For comparison, the mechanical properties and grain structure of $\beta$-tin are evaluated at different annealing conditions. Finally, the strengthening effect due to the intermetallics at different ageing states is evaluated by comparing the deformation behaviors of SAC solder and $\beta$-tin with similar grain size and composition. The relationship between the morphology and the strengthening effect due to intermetallics particles is discussed and the causes for the strength degradation in SAC solder during ageing are identified.

Key words: Pb-free solder, synchrotron x-ray tomography, focused ion beam tomography, intermetallics coarsening, dislocation plasticity, particle strengthening

\section{INTRODUCTION}

A large number of investigations have led to the development of many lead-free solder alloys like ternary $\mathrm{SnAgCu}(\mathrm{SAC})$ alloys which satisfy most of the technological requirements of the electronic industry. ${ }^{1,2}$ The solidified near-eutectic SAC solder consists of a $\beta$-Sn proeutectic phase with dendritic

(Received May 23, 2013; accepted January 9, 2014;

published online January 29, 2014) globules and an inter-dendritic eutectic mixture containing $\mathrm{Ag}_{3} \mathrm{Sn}$ and $\mathrm{Cu}_{6} \mathrm{Sn}_{5}$ intermetallic precipitates within a $\beta$-Sn matrix. ${ }^{3,4}$ In addition to good wetting property and interfacial fracture resistance, the finely distributed hard intermetallic compound (IMCs) particles present in near-eutectic SAC solder were shown to be responsible for its improved thermo-mechanical strength compared to other solder alloys. ${ }^{5-8}$ In fact, the deformation resistance of SAC solder in as-soldered condition was shown to be a function of the morphometrics of the dispersed 
intermetallics which are initially conditioned by the solidification cooling rate. ${ }^{9-11}$ However, it should be highlighted that the intermetallics in Sn-rich solders, due to the fast cooling rate used in fabrication and high homologous temperature of solder, are in meta-stable state even at room temperature and significant in situ microstructural evolution can take place by diffusion. ${ }^{11-13}$ This phenomenon causes a continuous variation in the deformation behavior of SAC solder joints during their service life which raises concerns on their long-term reliability. ${ }^{8,14-16}$

Several studies have addressed the problem of microstructural evolution in conventional and Sn-rich lead-free solders during isothermal aging. ${ }^{11-14,17}$ The $\mathrm{Ag}_{3} \mathrm{Sn}$ and $\mathrm{Cu}_{6} \mathrm{Sn}_{5}$ precipitates in SAC solders have been shown to grow considerably by Ostwald ripening, with a coarsening rate dependent on the ageing temperature. Intermetallic coarsening has also been reported to occur under thermomechanical cycling of SnAg-based solders, with the same mechanism but at a faster rate, particularly when the cyclic strain range is large. ${ }^{12,14,15}$ The work of Allen et al. ${ }^{11}$ and Fix et al. ${ }^{12}$ are among the primary investigations considering a quantitative analysis of the IMC coarsening in solder joints by performing $2 \mathrm{D}$ microstructural analyses at different ageing conditions. Sidhu and Chawla ${ }^{18,19}$ reconstructed the 3D distribution of $\mathrm{Ag}_{3} \mathrm{Sn}$ intermetallics in $\mathrm{Sn}-3.5 \mathrm{Ag}$ solder in as-soldered condition by mechanical serial sectioning. By comparing the morphometrics of IMCs obtained from $2 \mathrm{D}$ and $3 \mathrm{D}$ analyses, they demonstrated the necessity of a tomographic analysis for a reliable quantitative characterization of microstructural property and prediction of the deformation behavior of the solder. However, due to difficulties associated with the experimental techniques and the presence of microstructures at different scales, the $3 \mathrm{D}$ analysis of microstructural evolution in the SAC solder has not yet been addressed and the investigations published on this topic are limited to visualization of microstructures in binary $\mathrm{SnAg}$ solder alloys and only in as-soldered condition. 18,20

In addition to the microstructural evolution, the change in the mechanical behavior of Sn-rich solders has been extensively studied in recent years, ${ }^{5,8,15,21,22}$ concluding that ageing causes a considerable decrease in load-bearing capacity of the joint. The works of Haung et al. ${ }^{23}$ as well as Kerr and Chawla ${ }^{9}$ are among the first studies concerning the micro-mechanisms of deformation in Sn-rich solders. They suggested dislocation local climb over fine IMCs as the main mechanism governing the deformation behavior of Sn-rich solders. Based on their observations, Gong et al. ${ }^{8}$ developed a dislocation climbdetachment approach to represent the change in the mechanical response of Sn-3.5Ag solder by considering the change in the dislocation-IMCs interactions due to ageing. On this subject, the work of Dutta et al. ${ }^{15}$ should be highlighted, as they developed a microstructure-dependent phenomenological model for representing the evolution in the deformation behavior of solders. Maleki et al. ${ }^{24,25}$ attributed the change in the deformation behavior of solders to the change in the mechanical response of the eutectic mixture. By developing a numerical homogenization model, they confirmed that the strengthening effect of IMCs strongly depends on the 3D morphology and distribution of IMCs.

Due to the complex interdependency of the microstructure, grain structure, ageing condition, dislocation density, and yield strength of the solder joint, a comprehensive study focusing at the same time on a detailed 3D microstructural analysis and mechanical characterization can be very useful to achieve a truly quantitative understanding of the link between microstructure and macroscopic response of the solder. In this study, the evolution in microstructures of SAC solder at different scales are visualized in 3D during isothermal ageing by a combination of synchrotron x-ray and focused ion beam/scanning electron microscopy (FIB/SEM) tomography techniques. The region of interest is selected to represent the evolution of the bulk solder and thus purposely excludes the interface regions (minimum distance to interface is $250 \mu \mathrm{m}$ ). The change in the morphometrics of intermetallic particles is evaluated by statistical analyses of 3D reconstructed images and their rate of evolution is discussed based on the statistics. The effect of ageing on the crystalline structure of SAC solder is identified through electron backscatter diffraction (EBSD) orientation analysis. Macroscopic mechanical experiments are performed on the solder joints at different ageing conditions using a single lap shear test, and the change in the continuum stressstrain behavior of the solder is evaluated. To provide a basis for comparison, the mechanical properties and grain structure of $\beta$-tin, the "ductile matrix" of Sn-rich solder alloys, are determined at different annealing conditions and the correlation between its deformation behavior and grain structure is discussed. Finally, the change in the strengthening effect of IMCs caused by the change in their morphometry and distribution parameters is highlighted by comparing the deformation behavior of SAC solder and $\beta$-tin matrix with similar grain structures. Moreover, the capability of dislocation detachment models to predict the deformation behavior of solder based on the morphometrics of intermetallics is evaluated and discussed.

\section{EXPERIMENTAL METHODS}

\section{Material, Fabrication and Ageing Process}

In this study, near-eutectic SAC solder with a composition of Sn-4.0wt \%Ag-0.5wt \%Cu (SAC405) was used in the form of flux paste produced by AIM Solder (NC257-2 type T3; Montreal, Canada), containing powdered spherical metal particles with diameters of around $30 \mu \mathrm{m}$. The solder paste was reflowed on copper substrates using an optimized 
time-temperature profile consisting of a ramp from room temperature to $155^{\circ} \mathrm{C}$, dwelling for $100 \mathrm{~s}$ at this temperature, a ramp to peak temperature of $245{ }^{\circ} \mathrm{C}$ in $<150 \mathrm{~s}$, followed by a cooling in air to room temperature at the rate of $1{ }^{\circ} \mathrm{C} / \mathrm{s}$. Due to the sensitivity of the microstructures and consequently mechanical behavior of the joints to the reflow profile, ${ }^{26-29}$ the process parameters were kept constant during the fabrication of samples for tomography and mechanical testing. The surfaces of reflowed solders were subsequently polished to a final finish of $0.05 \mu \mathrm{m}$ with colloidal silica for further experiments.

It was shown in previous studies that the underlying microstructural evolution mechanism in SAC during isothermal ageing is similar in the range of $80-180^{\circ} \mathrm{C},{ }^{11,12,14}$ and thus temperature only affects the rate of coarsening. Thus, the ageing temperature was chosen equal to $150{ }^{\circ} \mathrm{C}$ in order to reach an acceptable amount of change in a reasonable ageing period. The main focus of this study is on microstructural/mechanical characterization of SAC solder at three ageing states: as-soldered condition, as well as aged for 144 and $296 \mathrm{~h}$ at $150{ }^{\circ} \mathrm{C}$ which represent the solders' microstructural and mechanical properties at moderately and highly aged conditions, respectively.* The ageing times were selected based on a preliminary study in order to reach a significant amount of ageing in a reasonable period and are representative of long-term use of SAC solders at elevated temperatures such as in high-availability servers, mission-critical electronics, or aerospace components. Here, the isothermal ageing was performed using a computercontrolled convection oven in air atmosphere.

\section{Tomographic Microstructure Characteriza- tion}

A 2D microscopy analysis was initially performed to identify appropriate tomographic techniques and parameters for further 3D microstructural analyses. The SEM image in Fig. 1a shows the microstructure in a typical SAC405 sample after isothermal ageing for $144 \mathrm{~h}$ at $150{ }^{\circ} \mathrm{C}$ and illustrates features with two distinct length-scales:

(1) Nano-scale structures including $\mathrm{Ag}_{3} \mathrm{Sn}$ and $\mathrm{Cu}_{6} \mathrm{Sn}_{5}$ intermetallics inside the eutectic mixture.

(2) Micro-scale structures including Sn dendrites, coarsened intermetallics and overall inter-dendritic eutectic mixture with typical dimensions of $\sim 5-50 \mu \mathrm{m}$.

Thanks to recent technological progress, various tomographic techniques nowadays exist by which microstructures with various sizes and properties can be characterized in $3 \mathrm{D}$. The capabilities/limita-

*The equations proposed by Dutta et al. ${ }^{14}$ can be used to extrapolate to other ageing times and temperatures. tions of different methods, in terms of typical achievable voxel dimensions and sampling volume per experiment, were compared by Uchic et al. ${ }^{30}$ and are graphically represented in Fig. 1b. On the basis of the data in Fig. $1 \mathrm{~b}$ and the size of microstructures in Fig. 1a, x-ray tomography was selected for nondestructive investigation of morphological changes in the micron-scale microstructures of SAC405 solder. Because of elevated and close x-ray absorption coefficients of the different constituents in SAC solder, a high energy and brightness synchrotron x-ray tomography was considered here to reach a reasonable contrast between the phases. Since the size of the nano-scale microstructures in solder is very close to the smallest achievable voxel size in the synchrotron $x$-ray tomography, the FIB/SEM nano-tomography technique was employed as a complement to study the morphology of IMC precipitates inside the eutectic mixture.

The TOMCAT beam-line of the Swiss Light Source (SLS) synchrotron in PSI, Villigen, Switzerland, was used for x-ray tomography of SAC solder. The scans were performed in absorption mode to reconstruct 3D images of phases with dissimilar absorption coefficients. $^{31,32}$ For an optimum experiment, the combination of sample thickness, x-ray energy, and exposure time should be selected in such a way to present enough x-ray transmission through all phases without saturation in the phases with lower $\mathrm{x}$-ray attenuation coefficients. ${ }^{31,33}$ Preliminary experiments on SAC solder showed that an x-ray flux of around $25 \mathrm{keV}$ presents the best quality. At this energy level, the thickness of the solder sample should be around $300 \mu \mathrm{m}$ to reach $\sim 20-40 \%$ of $\mathrm{x}$-ray transmission in all features. For this purpose, the solder joint was cut into small bars using a precise diamond wire cutting machine without damaging the sample (see geometry of the sample as well as the setup for x-ray tomography in Fig. 2). The sample was rotated on a stage over $180^{\circ}$ and 1,200 projection images were acquired. The exposure time was set to $1,200 \mathrm{~ms}$ for each projection which led to around $30 \mathrm{~min}$ of scanning time. The transmitted $\mathrm{x}$-rays after passing through the solder reach a LuAG:Ce scintillator which convert them to visible light recorded by a 2,048 pixel $\times 2,048$ pixel $\mathrm{CCD}$ camera through a $\times 20$ objective lens. To reach a spatial resolution of $0.37 \mu \mathrm{m}$, the field of view was limited to $757 \mu \mathrm{m}^{2} \times 757 \mu \mathrm{m}^{2}$. Finally, the microstructures were reconstructed from projections by Radon transformation resulting in generation of 2,046 sequential cross-section images corresponding to a cube with an edge size of $757 \mu \mathrm{m}$. As the solder joint was $1 \mathrm{~mm}$ thick, only the upper half of each joint, from mid-plane up to the interface, was scanned in each experiment. The scanned samples were aged for different periods and rescanned following the same protocol.

FIB/SEM tomography was carried out using a dual-beam Zeiss NVision 40 machine (Oberkochen, Germany) on dedicated specimens. Sequences of 2D 


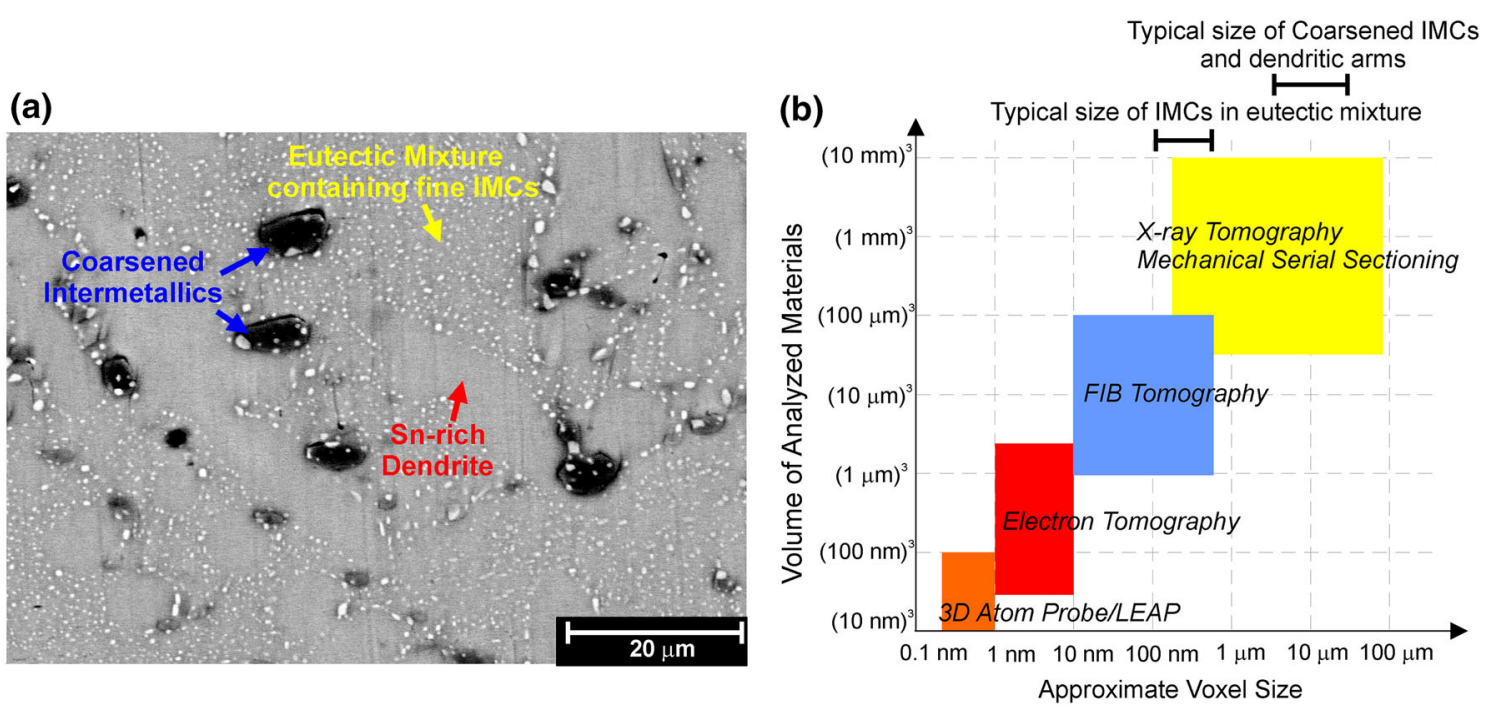

Fig. 1. (a) SEM micrograph of the microstructures in SAC405 solder after $144 \mathrm{~h}$ of ageing at $150{ }^{\circ} \mathrm{C}$. (b) Graphical representation of the resolution and typical volume analyzed per experiment in tomographic characterization methods ${ }^{30}$ versus typical size of the microstructures in solder.

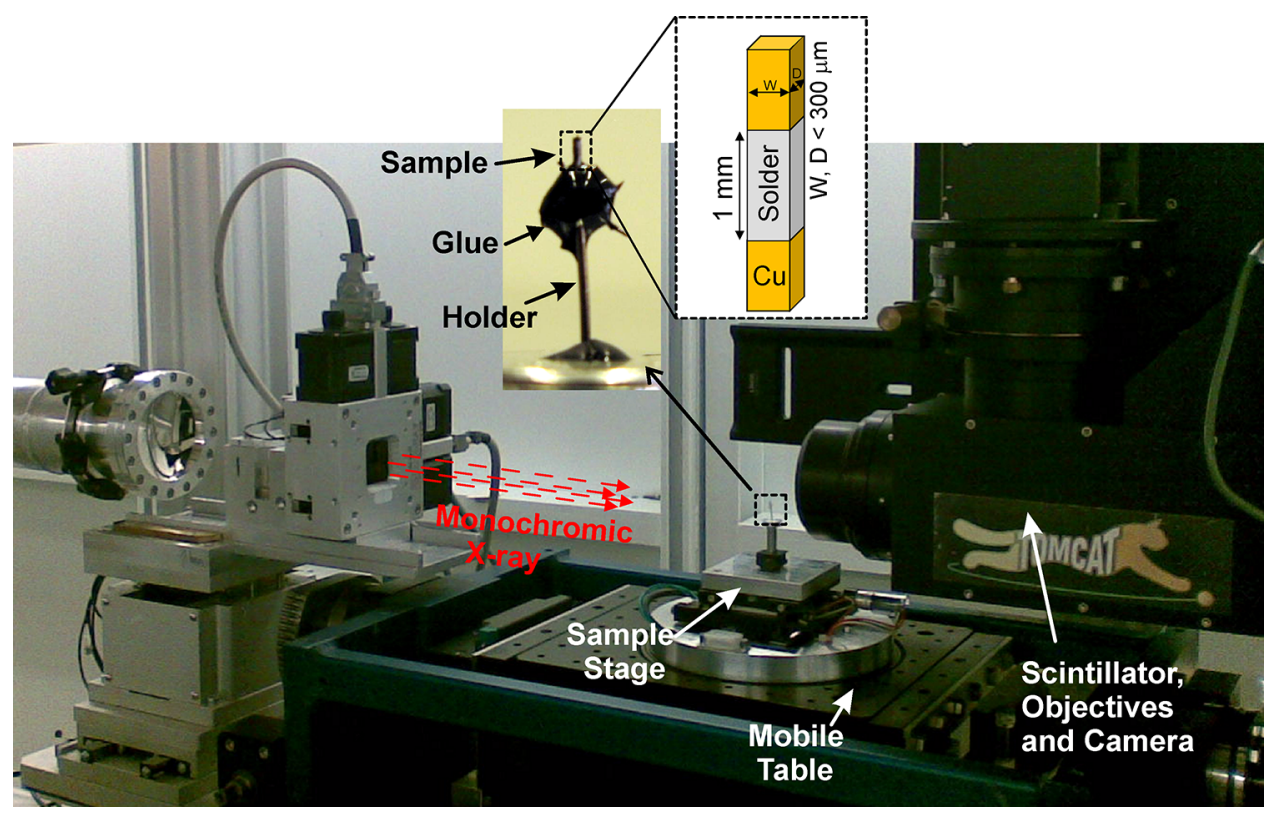

Fig. 2. Sample geometry and the setup employed for synchrotron x-ray tomography of SAC solder joints at the TOMCAT beamline of PSI.

cross-sections with a distance of $10 \mathrm{~nm}$ were milled by a $30 \mathrm{kV} \mathrm{Ga}^{+}$beam perpendicular to the surface of the solder sample. The secondary and back-scattered electron (SE and BSE) images of each section were captured with a resolution of $10 \mathrm{~nm}^{2} \times 10 \mathrm{~nm}^{2}$ at an accelerating voltage of $2 \mathrm{kV}$ by a high-resolution SEM adapted in the machine. Selecting a low voltage microscopy helped to reduce the electron interaction volume which appropriately resulted in clean nearsurface information in the obtained 2D images. A total number of 2,800 sections were milled in the experiments on as-soldered and aged solders which led to tomography of cubes with dimensions of approximately $21 \mu \mathrm{m} \times 15 \mu \mathrm{m} \times 28 \mu \mathrm{m}$.

\section{Grain Size/Orientation Analysis}

Electron back-scattered diffraction (EBSD) measurement was employed to study the grain properties such as their sizes, orientations, and boundaries in pure $\beta$-tin and SAC solder joints. In this study, a Philips XLF30-FEG SEM microscope (Eindhoven, Netherlands) equipped with a NordlysS II EBSD detector was used for orientation measurements. Euler angle and inverse pole figure (IPF) maps were reconstructed using acquired orientation datasets by HKL Oxford Instrument software package (Abingdon, UK). The grain boundaries were determined by a $5^{\circ}$ 


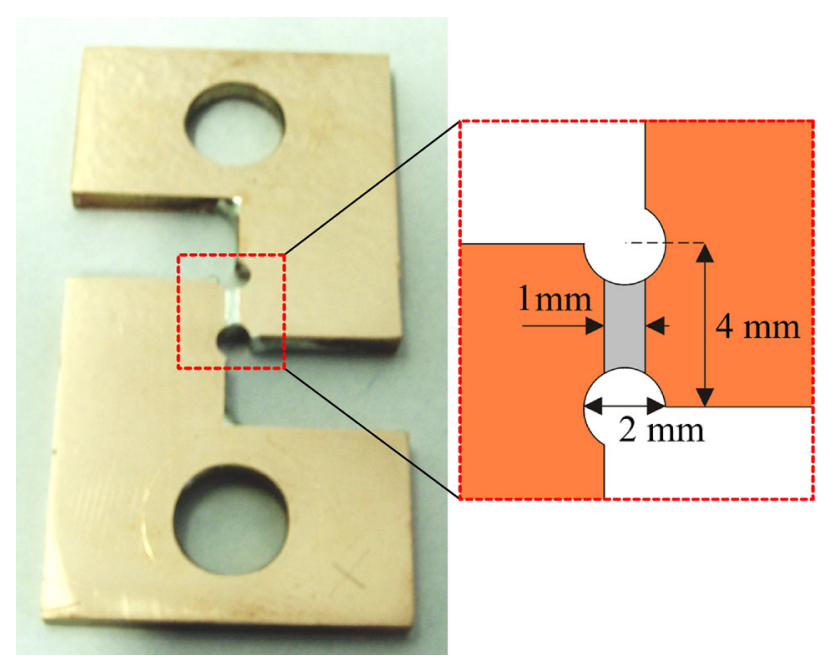

Fig. 3. Single lap shear specimen geometry employed for the characterization of deformation behavior of $\beta$-tin and SAC solder joint at different ageing conditions.

threshold on grain misorientation between neighboring pixels.

\section{Mechanical Characterization}

A single lap shear specimen design, with the geometry shown in Fig. 3, was used in this work for characterizing the deformation behavior of $\beta$-tin and solder joint. In comparison to tensile tests, the nearly uniform shear state, negligible normal stress, and low shear stress concentrations at the interface achieved in this design allow for testing over a larger strain range without damaging the interface $^{25}$ and thus provides good estimates of the properties of the bulk solder. The shear samples were produced as follows: the SAC405 or tin samples were reflowed according to the procedure described in "Material, Fabrication and Ageing Process". After polishing, the two lateral holes shown in Fig. 3 were drilled using a precisely aligned clamping fixture ensuring that the solder was not loaded nor damaged during operation. Displacement-controlled shear tests were performed at room temperature on an Instron 5848 MicroTester (Norwood, MA, USA) and the load was measured using a $2 \mathrm{kN}$ static Instron series 2530 load cell (linearity and repeatability $< \pm 0.025 \%$ full range). Due to the small size and complex geometry of the joints, a digital image correlation technique (DIC) was adapted for accurate evaluation of the displacements and eventually strain during shear testing.** For this purpose, a series of high-resolution images of the joint were captured during the test with a rate of 4 frames/s using an Olympus SZX12 optical microscope (Shinjuku, Tokyo, Japan)

\footnotetext{
**Using DIC technique for recording in-situ displacements has been found necessary to ensure that the compliance of the machine and test setup do not influence the end results of the tests.
}

and then processed in a custom-developed DIC software. It should be noted that, in this study, we focused on characterizing the elasto-plastic behavior of the solders at a unique shear strain rate of $0.40 \% / \mathrm{s}$ which corresponds to an equivalent uniaxial strain rate of $0.24 \% / \mathrm{s}$. Finally, steady state creep tests were performed on the same single lap shear joint design at $23{ }^{\circ} \mathrm{C}$ for a range of shear stresses from 7.5 to $17 \mathrm{MPa}$ in both as soldered state and $144 \mathrm{~h}$ of ageing at $150{ }^{\circ} \mathrm{C}$ condition. For these tests, the Instron 5848 Microtester was equipped with a $100 \mathrm{~N}$ load cell ( $0.2 \%$ accuracy) and the steady state shear strain rate was recorded using the internal displacement transducer of the machine $(1 \mu \mathrm{m}$ resolution) up to $1 \%$ engineering shear strain. These creep test conditions represented only the high stress creep regime of the solder and were thus fitted using a single power-law term.

\section{RESULTS AND DISCUSSION}

\section{Microstructural Evolution in the Bulk Solder}

\section{$3 D$ Configuration of the Microstructures}

Typical reconstructed cross-section images obtained from synchrotron x-ray tomography of the same SAC solder sample are shown in Fig. 4 for as-soldered condition and after 144 and $296 \mathrm{~h}$ of ageing. The sufficient contrast between the tin dendrites and surrounding eutectic phase in Fig. 4a make them easily distinguishable. However, the intermetallic particles in the eutectic mixture of asreflowed solder are not visible here, since their size is close to the image resolution as discussed in "Tomographic Microstructure Characterization". It should be noted that the contrast between pro-eutectic dendrites and eutectic tin gradually decreases during ageing, in such a way that, after $296 \mathrm{~h}$ of ageing, they become hardly distinguishable (see Fig. 4c). The images in Fig. 4b, c show an appearance and growth of light gray and very bright features which represent the coarsened intermetallic particles within the matrix. In order to identify the relationship between the chemical compositions and intensity of these features for further segmentation, an aged sample was mounted into epoxy and precisely cut parallel to the solder-copper interface plane without imposing extensive damage. The element map of the created cross-section was identified by energy-dispersive $\mathrm{x}$-ray spectroscopy (EDX) analyses and was compared with the corresponding $x$-ray tomographic image. The analysis indicated that gray and bright features in the tomographic image represent $\mathrm{Cu}_{6} \mathrm{Sn}_{5}$ and $\mathrm{Ag}_{3} \mathrm{Sn}$ intermetallics, respectively. The intensity range related to the different microstructures were identified manually and used for threshold segmentation. The segmented features were visualized in 3D by stacking the 2D slices together using ITK-Snap software package. Reconstructed image of microscale microstructures (dendrites and coarsened 

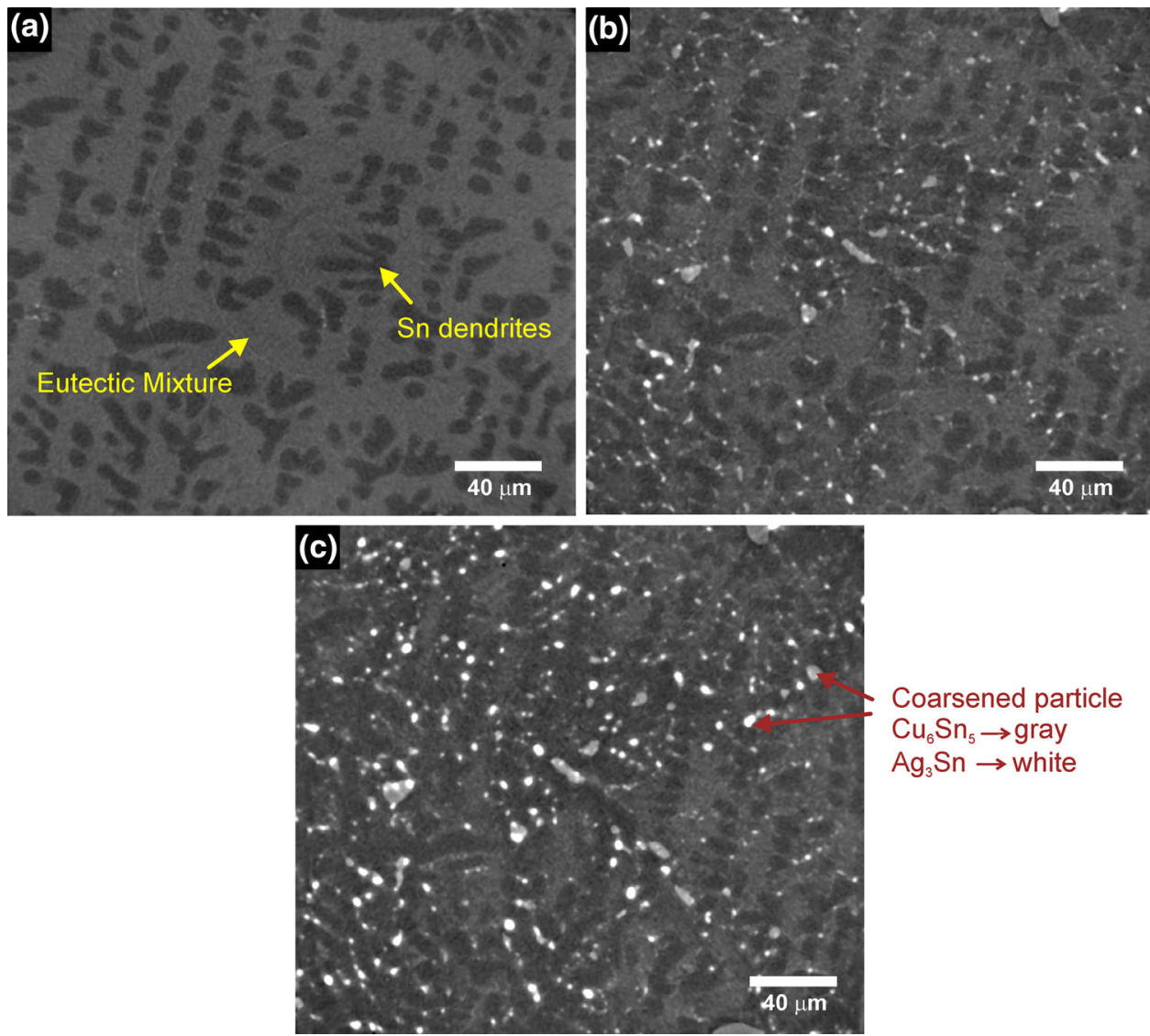

Fig. 4. Microstructures in typical reconstructed cross-section images obtained from synchrotron x-ray tomography in (a) as-soldered condition and after (b) $144 \mathrm{~h}$ and (c) $296 \mathrm{~h}$ of ageing at $150^{\circ} \mathrm{C}$, indicating sufficient contrast between Sn-rich dendrites and surrounding eutectic mixture.

intermetallic particles) of a typical SAC solder in as-soldered condition and after 144 and $296 \mathrm{~h}$ of ageing at $150{ }^{\circ} \mathrm{C}$ are illustrated in Fig. $5 \mathrm{a}$, b,and c, respectively.

A two-dimensional SE + BSE image of a typical ion milled cross-section of an as-soldered eutectic phase, captured during FIB/SEM tomography, is shown in Fig. 6. The superimposed colored signs show the results of EDX analysis over selected points inside the eutectic phase indicating a sufficient contrast between the $\mathrm{Ag}_{3} \mathrm{Sn}$ and $\mathrm{Cu}_{6} \mathrm{Sn}_{5}$ particles and surrounding eutectic tin. Taking advantage of this particularity, the sub-micron intermetallics inside the eutectic phase of SAC solder were visualized in $3 \mathrm{D}$ via threshold segmentation of the FIB SE + BSE images. Examples of reconstructed microstructures of $\mathrm{Ag}_{3} \mathrm{Sn}$ and $\mathrm{Cu}_{6} \mathrm{Sn}_{5}$ intermetallics in a region of $6 \mu \mathrm{m} \times$ $6 \mu \mathrm{m} \times 6 \mu \mathrm{m}$ of ternary eutectic mixture in as-soldered condition and after $144 \mathrm{~h}$ of ageing are shown in Fig. 5d, e. Since the voxel size in the FIB/SEM tomography is much smaller than the dimensions of the features, the $3 \mathrm{D}$ segmented images certainly yield detailed information for all intermetallics in the eutectic phase. It should be noted that, in the case of solder aged for $296 \mathrm{~h}$, the micro-scale x-ray tomography is sufficient to reveal all levels of the microstructure in the solder (see Fig. 5c), as it only contains coarsened particles dispersed in the tin matrix and there is no more distinguishable eutectic phase.

In addition, the segmentation results show occasional presence of large leaf-shape $\mathrm{Ag}_{3} \mathrm{Sn}$ plates over the interfacial $\mathrm{Cu}_{6} \mathrm{Sn}_{5}$ intermetallic layer as well as long hollow $\mathrm{Cu}_{6} \mathrm{Sn}_{5}$ whiskers in the bulk SAC405 solder in the as-soldered condition. The 3D reconstructed configurations of these features in a typical cube of SAC405 solder with an edge size of $200 \mu \mathrm{m}$ are shown in Fig. 7. Formation of these joint-scale intermetallics flakes or platelets in the Sn-rich alloys with high percentages of $\mathrm{Cu}$ and $\mathrm{Ag}$ (more than $3.9 \mathrm{wt} \% \mathrm{Ag}$ and $0.5 \mathrm{wt} \% \mathrm{Cu}$ ) have been previously reported and several explanations have been proposed for their nucleation sites and formation mechanisms. ${ }^{34-36}$ The tomographic results indicated that these features are stable and their morphology remains unchanged during isothermal ageing up to $296 \mathrm{~h}$ at $150{ }^{\circ} \mathrm{C}$. It should be noted that these microstructures were observed in only $\sim 10 \%$ of the samples.

\section{Quantitative/Kinetic Analysis of Evolution in Morphology of the IMCs}

The tomography results showed that the SAC405 solder in as-reflowed condition contained $30 \pm 6.2 \mathrm{vol} \%$ 


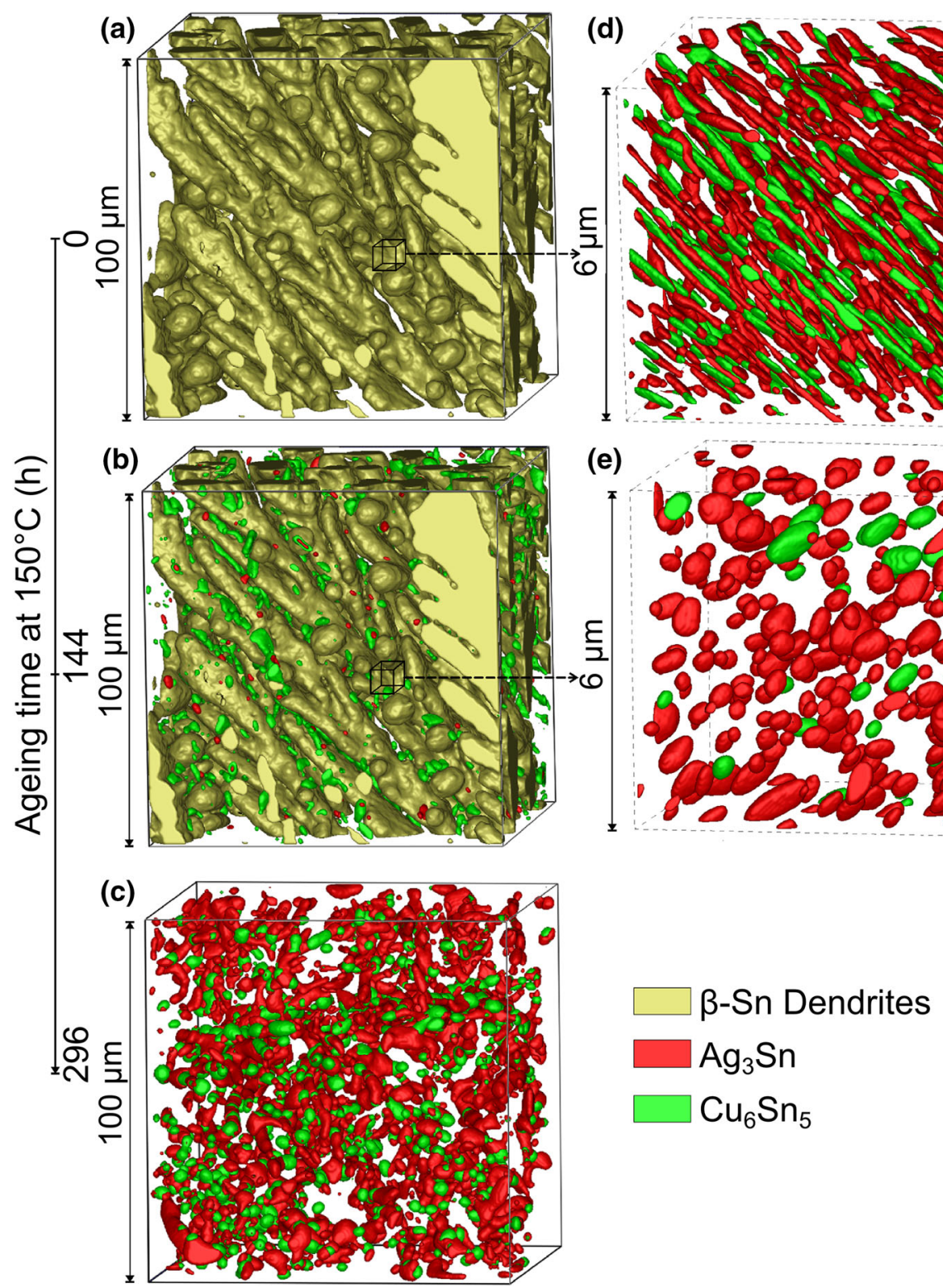

Fig. 5. 3D segmented images of microstructures in a typical SAC405 solder showing coarsening and spheroidizing of fine IMCs during isothermal ageing for $0 \mathrm{~h}(\mathrm{a}, \mathrm{d}), 144 \mathrm{~h}(\mathrm{~b}, \mathrm{e})$ and $296 \mathrm{~h}(\mathrm{c})$ at $150{ }^{\circ} \mathrm{C}$ visualized by combination of x-ray $(\mathrm{a}-\mathrm{c})$ and FIB/SEM tomography (d, e).

of $\beta$-Sn dendrites. The remaining was a eutectic mixture which consisted of 8.5 vol\% sub-micron needle-shape IMCs (see Fig. 5a, d) in a Sn matrix. Comparison of the microstructures in Fig. 5 indicates that, although the morphology of dendrites in SAC solder remained almost stable, the ageing for $144 \mathrm{~h}$ at $150{ }^{\circ} \mathrm{C}$ caused the transformation of a portion of fine particles into large coarsened IMCs as shown in Fig. 5b. Upon further ageing, the coarsening continued to form larger intermetallics in such a way that almost all the fine intermetallic precipitates grew to larger features after $296 \mathrm{~h}$ of ageing at $150{ }^{\circ} \mathrm{C}$, as shown in Fig. 5c. In order to quantitatively assess the intermetallics coarsening behavior, the average volume of particles in each ageing condition was identified as follows: the total volumes of $\mathrm{Cu}_{6} \mathrm{Sn}_{5}$ and
$\mathrm{Ag}_{3} \mathrm{Sn}$ particles were determined by summation of segmented voxel volumes in that phase; the number of individual particles (disconnected segmented regions) was computed through a $3 \mathrm{D}$ image quantitative analysis; and the average volume of individual intermetallics particles were eventually computed by dividing the total volume of IMCs by the number of particles. The summary of quantification results is shown in Fig. 8 where the error bars show the minmax range of average particle volume in at least three scanned samples at each ageing condition. The results indicate that the average volume of both types of intermetallics particles continuously increased due to isothermal ageing to reach an average volume of $\sim 6 \mu \mathrm{m}^{3}$ for $\mathrm{Ag}_{3} \mathrm{Sn}$ and $\sim 17 \mu \mathrm{m}^{3}$ for $\mathrm{Cu}_{6} \mathrm{Sn}_{5}$ (corresponding, respectively, to $\sim 7.2 \mathrm{Ag}_{3} \mathrm{Sn}$ and $\sim 0.98$ 


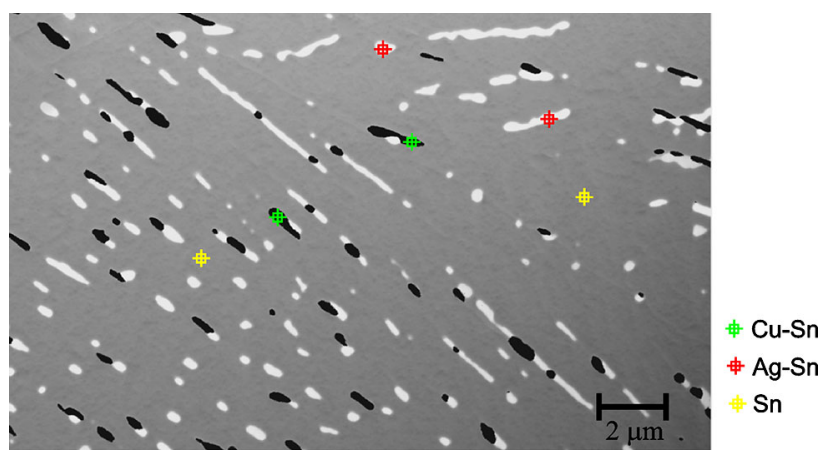

Fig. 6. SE + BSE micrograph of a typical ion-milled cross-section of eutectic mixture in as-soldered SAC405 obtained during FIB/SEM tomography and relevant EDX results showing considerable contrast between sub-micron $\mathrm{Ag}_{3} \mathrm{Sn}$ and $\mathrm{Cu}_{6} \mathrm{Sn}_{5} \mathrm{IMCs}$ and tin matrix.

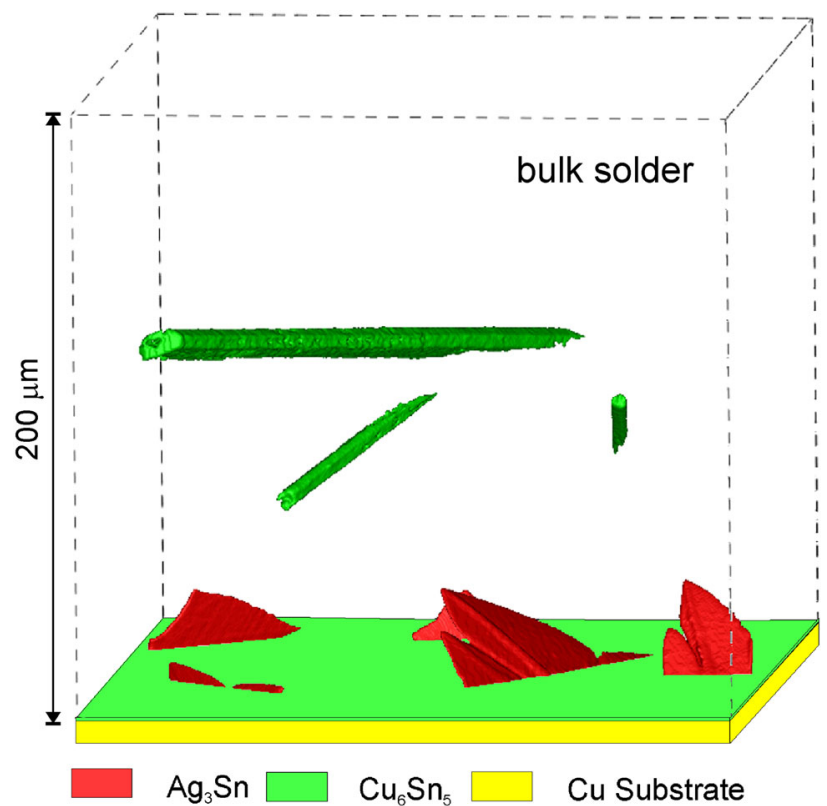

Fig. 7. 3D distribution of leaf-shape $\mathrm{Ag}_{3} \mathrm{Sn}$ plates over the interfacial layer and long $\mathrm{Cu}_{6} \mathrm{Sn}_{5}$ whiskers in a typical SAC405 solder joints which remained unchanged during ageing.

$\mathrm{Cu}_{6} \mathrm{Sn}_{5}$ particles in a cube of $10 \mu \mathrm{m}^{3} \times 10 \mu \mathrm{m}^{3} \times$ $10 \mu \mathrm{m}^{3}$ ) after $296 \mathrm{~h}$ of ageing. ${ }^{\dagger}$ The coarsened $\mathrm{Cu}_{6} \mathrm{Sn}_{5}$ particles were found to be generally much larger than $\mathrm{Ag}_{3} \mathrm{Sn}$ ones and grew with higher rates during ageing. This is in good agreement with what was reported by Allen et al. ${ }^{11}$ The growth of large intermetallics in a SnAg-based solder alloy can be described by diffusion according to the so-called Ostwald ripening mechanism. ${ }^{11-13}$ The latter is defined as the creation of larger features by dissolving smaller size microstructures which have a higher interfacial energy than the larger ones. Assuming that the coarsened particles have spherical shapes,

These numbers correspond to a total volume fraction of $4.34 \%$ of $\mathrm{Ag}_{3} \mathrm{Sn}$ and $1.68 \%$ of $\mathrm{Cu}_{6} \mathrm{Sn}_{5}$.

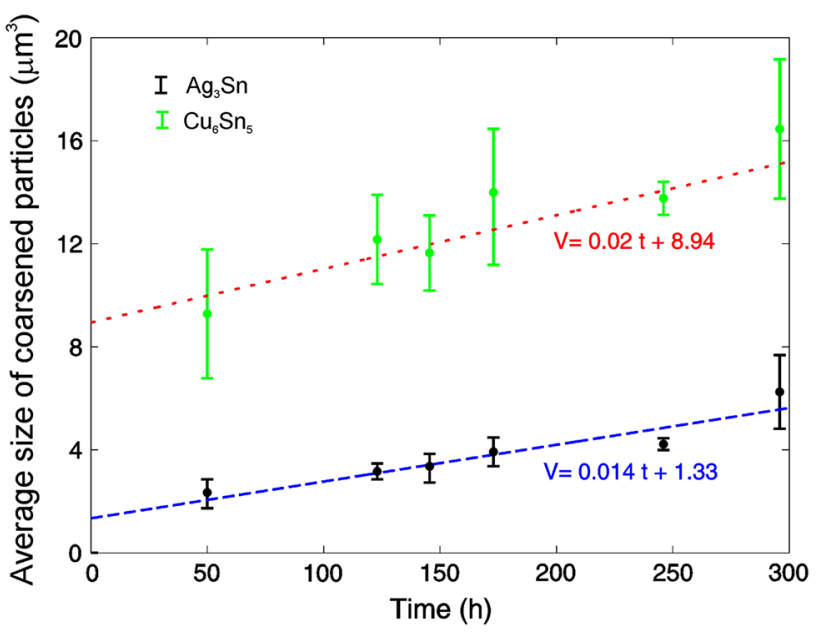

Fig. 8. Evolution in average size of coarsened intermetallic particle during ageing at $150{ }^{\circ} \mathrm{C}$ obtained by 3D statistical analyses.

the kinetics of solid state particle growth can be modeled by: ${ }^{17}$

$$
R^{n}-R_{0}^{n}=K_{0} t \exp \left(\frac{-Q}{R T}\right)
$$

where $R_{0}$ and $R$ are the mean particle radii at time 0 and $t, n$ is the growth exponent, $K_{0}$ is a constant and indicator of coarsening rate, $t$ is the ageing time, $Q$ is the activation energy of the relevant diffusion process, $T$ is the absolute temperature, and $\mathrm{R}$ is the universal gas constant. The value of $n$ in Eq. 1 depends on the rate-controlling diffusion mechanism. Indeed, $n=4$ represents grain boundary diffusion, while $n=3$ corresponds to the case of volume diffusion. ${ }^{13,17}$ Thus, for an isothermal ageing condition and when the bulk diffusion is the rate-controlling mechanism, a linear relationship between the increment in average volume of particles, $\Delta V$, and ageing time is expected. Thus, Eq. 1 can be written as:

$$
\Delta V=K t, \quad K=\frac{4}{3} \pi K_{0} \exp \left(\frac{-Q}{\mathrm{RT}}\right)=c t e
$$

Interestingly, comparison of the experimental data in Fig. 8 and the corresponding fitted lines indicates an acceptably linear relationship between the average volumes of both particle types and ageing time. This agreement confirms that volume diffusion is the main mechanism for particle coarsening during isothermal ageing of SAC solder. It should be noted that, due to the low density of grain boundaries in Sn-rich lead-free solders, the volume diffusion has been previously suggested as the potential mechanism responsible for the evolution in intermetallics during ageing, ${ }^{11,12}$ which is experimentally confirmed here through a $3 \mathrm{D}$ statistical analysis. Thus, the coarsening rate coefficients, $K_{0}$, of $\mathrm{Cu}_{6} \mathrm{Sn}_{5}$ and $\mathrm{Ag}_{3} \mathrm{Sn}$ particles are 

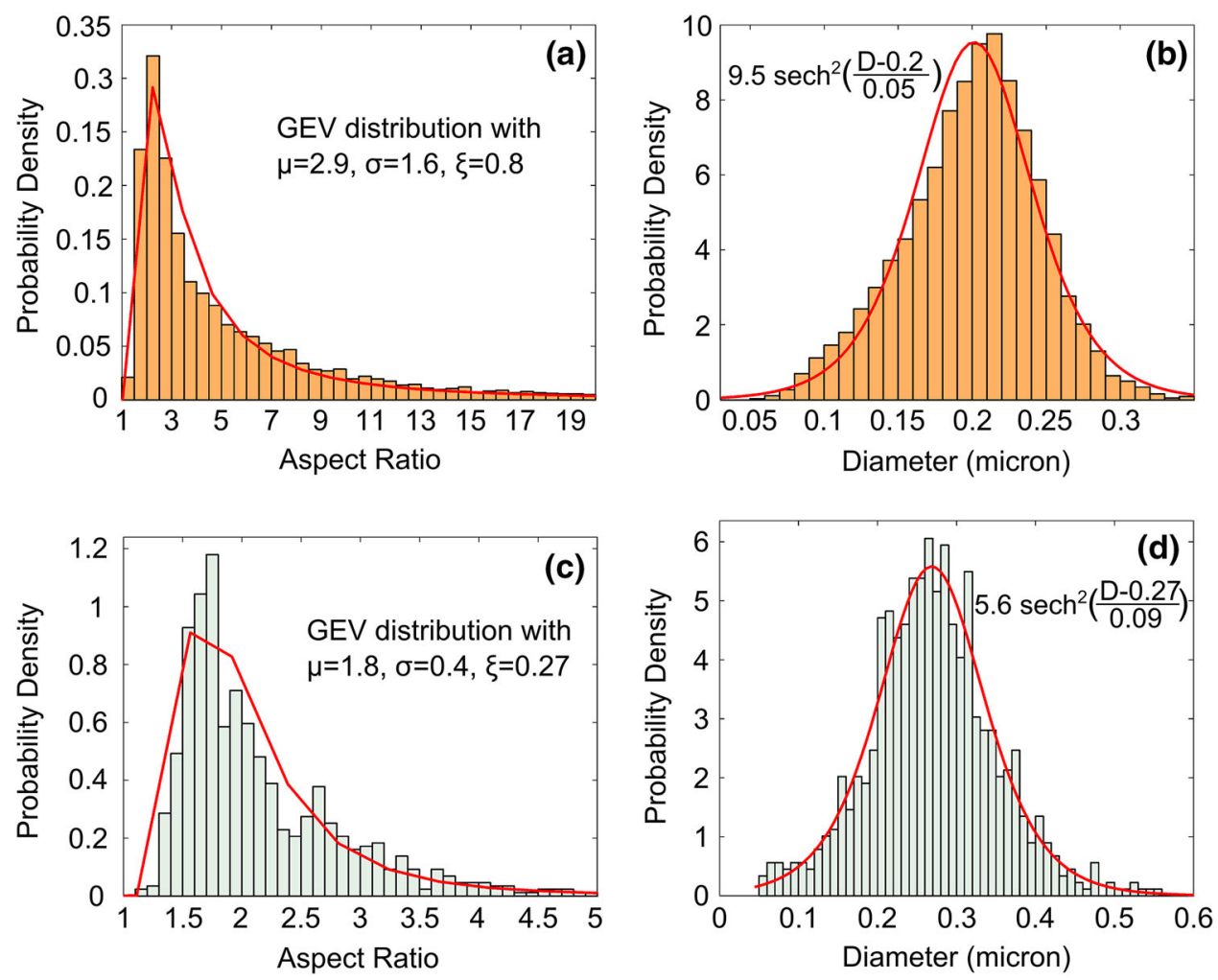

Fig. 9. Probability density distributions of diameter and aspect ratio of the IMCs in the eutectic mixture of SAC405 solder (a, b) at the as-soldered state, and (c, d) after $144 \mathrm{~h}$ of ageing at $150{ }^{\circ} \mathrm{C}$.

estimated, respectively, as $1.6 \times 10^{-12}$ and $1.17 \times 10^{-12} \mathrm{~m}^{3} / \mathrm{s}$ by considering the identified $K$ values in Fig. 8 and assuming an effective activation energy of $69 \mathrm{~kJ} / \mathrm{mol}$ for diffusion control mechanism. ${ }^{11}$

In addition to coarsening, the comparison of the 3D configuration of IMC in the eutectic phase for as-soldered and $144 \mathrm{~h}$ aged conditions (Fig. 5d, e) indicates an evolution from needle-shape intermetallics to a more spherical-shape with less surface energy during ageing. For better clarity, aspect-ratios as well as diameters of more than 800 IMC particles in eutectic mixture in as-soldered state and after $144 \mathrm{~h}$ of ageing were individually determined by using a set of quantification tools in AVIZO-Fire software (FEI VSG; Mérignac, France) and are reported in the histograms of Fig. 9. The probability density distributions in Fig. 9a, c demonstrate a clear decrease in the aspect ratio of the intermetallics due to ageing. Thus, the ageing for $144 \mathrm{~h}$ was identified to cause a decrease in the average aspect ratio of particles from $\sim 4$ to 2 . The statistics indicated an increase in the average diameter, $D_{\text {ave }}$, of the IMCs in the eutectic mixture from $205 \mathrm{~nm}$ in as-soldered state to $310 \mathrm{~nm}$ after $144 \mathrm{~h}$ of ageing. Moreover, after $296 \mathrm{~h}$ of ageing, most of the fine intermetallics grew to large spherical particles with $D_{\text {ave }}=3.3 \mu \mathrm{m}$. Conversely, geometrical analyses showed that the average inter-particle spacing, $\lambda$, increased from $630 \mathrm{~nm}$ in the as-soldered state to
$1.2 \mu \mathrm{m}$ and finally $9.5 \mu \mathrm{m}$ during the ageing for 144 and $296 \mathrm{~h}$ at $150^{\circ} \mathrm{C}$. A more detailed analysis of the evolution of the structure of the eutectic mixture can be found in. ${ }^{24,25}$

It has also been observed that the intermetallic needles in as-soldered condition follow a preferred orientation which is connected to the orientation of the corresponding eutectic grain. ${ }^{25}$ High lattice strain mismatch between the crystal lattices of the precipitates (IMCs) and the matrix (Sn) have been proposed to explain the formation of needle-shape particles during solidification. ${ }^{37}$ It should also be noted that a similar microstructural evolution is to be expected during isothermal ageing at other temperatures up to $180^{\circ} \mathrm{C}$, since it was demonstrated in ${ }^{11,12,14}$ that, in this range, the ageing temperature only affects the rate of evolution and not its underlying mechanism.

\section{Change in Overall Volume Fraction of the IMCs and Their Surface Energy}

The total volume fraction of intermetallics $\left(\mathrm{Cu}_{6} \mathrm{Sn}_{5}+\mathrm{Ag}_{3} \mathrm{Sn}\right)$ over the bulk solder, $F_{\text {IMC-total, }}$ was computed from the tomographic results by the following expression:

$$
F_{\text {IMC-total }}=F_{\text {IMC-Eut. }} \times F_{\text {Eut. }}+F_{\text {IMC-coarsened }},
$$

where $F_{\text {IMC-Eut. }}$ is the volume fractions of the IMCs in the eutectic phase; $F_{\text {IMC-coarsened }}$ is the volume fraction 


\section{Table I. Mean volume fractions of constituents in the SAC405 solder joint during ageing}

\begin{tabular}{|c|c|c|c|c|}
\hline Ageing condition & $F_{\text {IMC-Eut. }}(\%)$ & $F_{\text {IMC-coarsened }}(\%)$ & $F_{\text {Eut. }}(\%)$ & $F_{\text {IMC-total }}(\%)$ \\
\hline As-soldered & $8.6 \pm 0.3$ & 0 & $70 \pm 6.2$ & 6.0 \\
\hline Aged for $144 \mathrm{~h}$ at $150^{\circ} \mathrm{C}$ & $3.5 \pm 0.4$ & $3.2 \pm 0.3$ & $67 \pm 5.0$ & 5.6 \\
\hline Aged for $296 \mathrm{~h}$ at $150{ }^{\circ} \mathrm{C}$ & $<0.1$ & $6.3 \pm 0.5$ & - & 6.3 \\
\hline
\end{tabular}

of coarsened IMCs over whole bulk solder, and $F_{\text {Eut. }}$ is volume fraction of the eutectic phase. The mean values of $F_{\text {IMC-Eut. }} F_{\text {Eut. }}, F_{\text {IMC-coarsened }}$ obtained from tomographic analyses as well as the computed $F_{\text {IMC-total }}$ are summarized in Table I. Comparison of the data in the three conditions showed that the total volume fractions of the intermetallic precipitates in the SAC solder remained almost constant during isothermal ageing at $150{ }^{\circ} \mathrm{C}$, although their morphology underwent significant changes. This fact can be attributed to the low concentration of solute atoms in $\beta$-tin matrix and negligible diffusion from the substrate to the bulk solder.

In a two-phase material containing uniform distribution of $\gamma$-phase spherical particles of radius $R$ and constant volume fraction of $F_{\gamma}$ in a $\alpha$-matrix, the surface energy density, $E_{\mathrm{v}}$, can be estimated by:

$$
E_{\mathrm{v}}=\gamma_{\alpha \gamma} N_{\mathrm{v}}\left(4 \pi R^{2}\right)=\gamma_{\alpha \gamma} N_{\mathrm{v}}\left[\frac{3 F_{\gamma}}{4 \pi N_{\mathrm{v}}}\right]^{2 / 3}
$$

where $\gamma_{\alpha \gamma}$ is interface energy of $\alpha / \gamma$ phase and $N_{\mathrm{v}}$ is number of particles per unit volume. ${ }^{37}$ Considering a local equilibrium across the $\alpha / \gamma$ interface $\left(\gamma_{\alpha \gamma} \sim\right.$ constant) and negligible curvature effects, Eq. 4 implies that $E_{\mathrm{v}} \propto N_{\mathrm{v}}^{1 / 3}$. The 3D statistical analyses of tomographic images showed that the average number of IMC particles per unit volume of solder decreased from $2.6 \mu \mathrm{m}^{-3}$ in as-soldered condition to $4.2 \times 10^{-4} \mu \mathrm{m}^{-3}$ after $296 \mathrm{~h}$ of ageing at $150{ }^{\circ} \mathrm{C}$. On this basis and considering $E_{\mathrm{v}} \propto N_{\mathrm{v}}^{1 / 3}$, the ageing for $296 \mathrm{~h}$ at $150{ }^{\circ} \mathrm{C}$ would cause a $94 \%$ decrease in the surface energy of the system which explains how the observed morphology changes drive the system towards a more energetically stable condition.

In order to verify the tomography results, the total mass of each element (i.e. $\mathrm{Sn}, \mathrm{Ag}$, and $\mathrm{Cu}$ ) in the SAC405 solder was calculated based on the data in Table I and compared with that of the raw solder paste employed in the fabrication. For simplicity in the calculations, the solubility of pure elements in each other was considered negligible. ${ }^{38 *}$ The room temperature densities of phases were selected as $\rho_{\text {Sn }}=7.3 \mathrm{~g} / \mathrm{cc}, \rho_{\mathrm{Ag}_{3} \mathrm{Sn}_{3}}=10 \mathrm{~g} / \mathrm{cc}$ and $\rho_{\mathrm{Cu}_{6} \mathrm{Sn}_{5}}=8.3 \mathrm{~g} / \mathrm{cc}$ in the calculations. ${ }^{39}$ The element mass fractions computed based on the tomography results were identified as $95 \mathrm{wt} \% \mathrm{Sn}, 4.2 \mathrm{wt} \% \mathrm{Ag}$ and $0.8 \mathrm{wt} \%$ $\mathrm{Cu}$, which corresponded well, within measurement uncertainties, with the nominal composition of the

${ }^{\ddagger}$ The $\mathrm{SnAgCu}$ phase diagram ${ }^{37}$ shows a negligible solid solubility of $\mathrm{Ag}$ and $\mathrm{Cu}$ in Sn-matrix of SAC405 at room temperature. solder paste used. This agreement demonstrates the consistency of the present tomography results and morphometry analysis. As a consequence, this also demonstrates that although pure copper substrates and no ENIG/OSP or other pad finish were used to protect the joint from potential diffusion of $\mathrm{Cu}$ at the solder interfaces, the composition of the bulk solder did not change during the ageing experiment. ${ }^{\S}$

\section{Evolution in the Granular Structure}

SAC solder alloys are polycrystalline and it is well known that grain size, recrystallization, and relevant mechanisms like grain boundary sliding and decohesion may affect the mechanical properties of polycrystalline materials. ${ }^{7,40,41}$ Hence, to gain a sound understanding of the deformation mechanisms of the solder, the change in its crystalline microstructure during ageing also needs to be investigated. For this purpose, the 2D orientation map of SAC405 solders in as-soldered condition was initially identified by EBSD analysis. The samples were then aged for $144 \mathrm{~h}$ and subsequently $296 \mathrm{~h}$ at $150{ }^{\circ} \mathrm{C}$, polished very slightly to remove the oxides from their surfaces, and reanalyzed. Since eutectic tin and tin dendrites have the same lattice structures (tetragonal with lattice parameters of $a=5.83 \AA$ and $c=3.18 \AA^{7}$ ), a single scanning gave detailed orientation properties of all grains. Figure 10a, b shows the orientation maps and unit cells of the main grains of a typical solder sample in as-soldered condition and after $296 \mathrm{~h}$ of ageing with grain boundary lines corresponding to $5^{\circ}$ of misorientations. The results demonstrated the presence of large grains $(D>200 \mu \mathrm{m})$ without any clear preferred orientation in SAC solder. Minor evolution and high stability of the grain structure during ageing was also observed based on misorientation histogram analysis and comparison of discrete pole figures as shown in Fig. 10c, d. This highlights the fact that, in these isothermal and nearly stress-free ageing conditions, the microstructural evolution in SAC solder was mainly limited to the morphological change in IMCs discussed earlier. It should be noted that the grain size usually depend on the cooling rate during solidification as slower cooling provides more time for grain growth and leads to the formation of even bigger grains. ${ }^{7}$ Moreover, analysis of the resulting orientation

\footnotetext{
${ }^{\S}$ However, it should be noted that significant morphology changes were observed (IMC layer growth, change of IMC particle morphology) close to the interfaces (within $\sim 50 \mathrm{~m}$ distance from the interface) but these were outside of the region of interest studied here.
} 

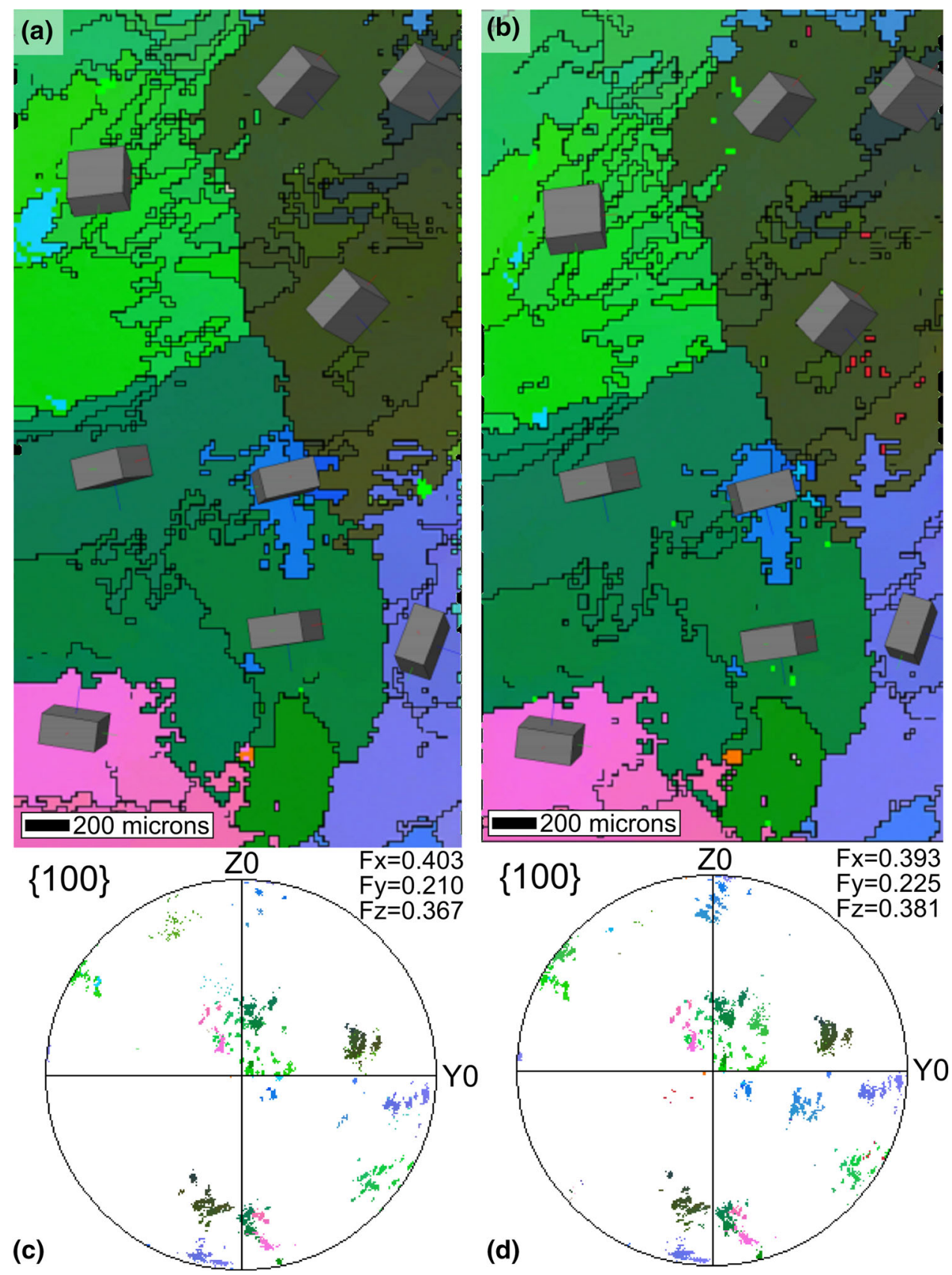

Fig. 10. Orientation map and discrete pole figure of Sn in SAC405 joint (a, c) in as-soldered condition and (b, d) after $296 \mathrm{~h}$ ageing at $150{ }^{\circ} \mathrm{C}$, indicating a large and stable crystalline grain structure.

maps showed that the orientation of $\beta$-Sn dendrites was mostly consistent with that of the surrounding $\beta$-Sn matrix. Since the $\beta$-Sn dendrites nucleate and grow before the eutectic tin matrix, ${ }^{3,40}$ it can be interpreted that the eutectic tin matrix of SAC solder was grown from the pre-existing $\mathrm{Sn}$ dendrites surfaces.

\section{Evolution in Macroscopic Deformation Behavior of the Solder During Ageing}

The stress-strain behavior of SAC solder joints were characterized at the three considered ageing conditions (as-soldered, and aged for 144 and $296 \mathrm{~h}$ at $150{ }^{\circ} \mathrm{C}$ ) to determine the effects of the identified microstructural evolutions on the mechanical properties. At least three identical shear tests were considered at each state to identify the representative response of the solder joint. A summary of the experimental results is presented in Fig. 11a. The lines and error bars in Fig. 11a represent the average equivalent stress and corresponding standard deviations at each strain value. Note that the reported equivalent stress and strain values were computed from the corresponding values in shear, considering a pure shear state. The test data 

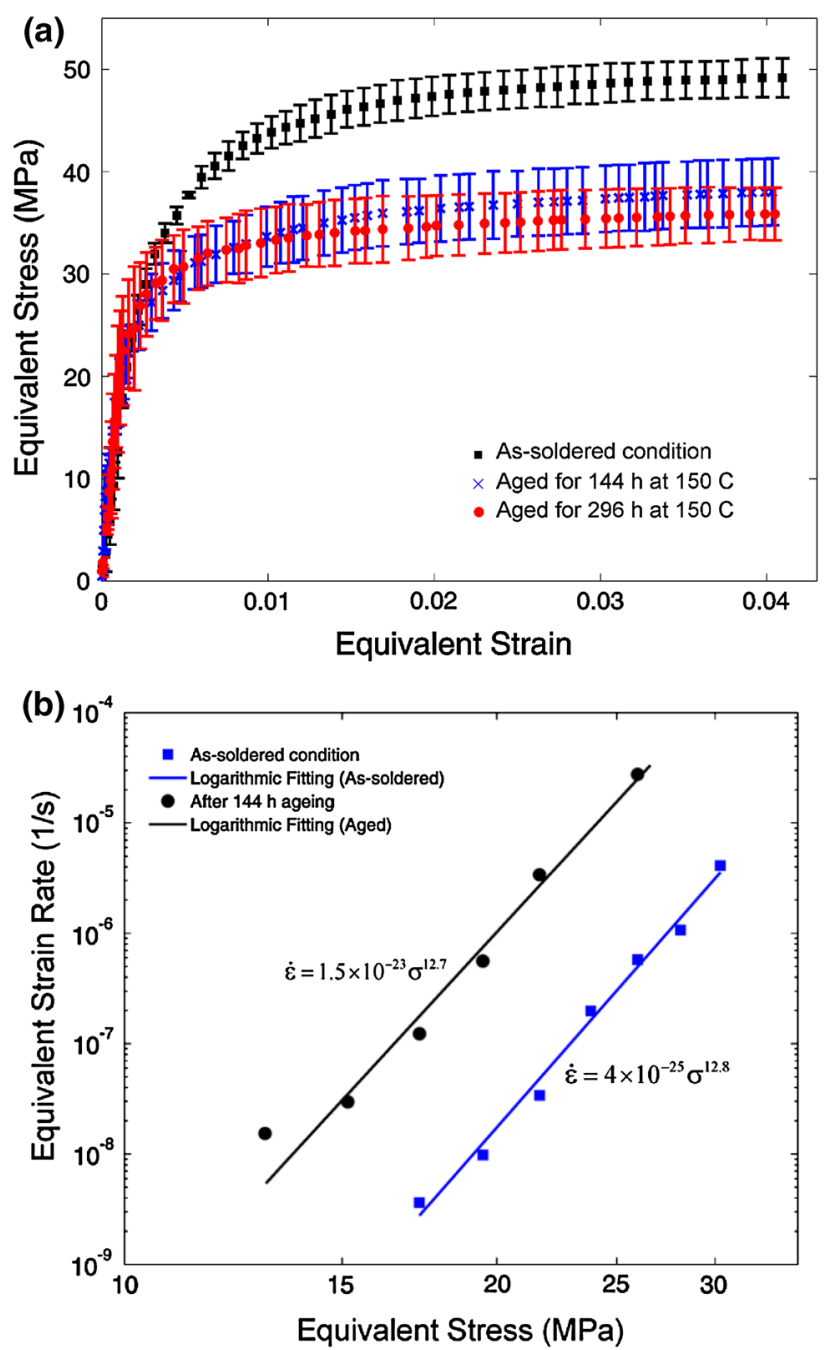

Fig. 11. (a) Mises equivalent stress-strain response of SAC405 solder joints at different ageing conditions at $0.24 \% / \mathrm{s}$ strain rate. (b) steady state creep response of SAC405 joint in as-soldered state and after $144 \mathrm{~h}$ of ageing at $150{ }^{\circ} \mathrm{C}$ (tests performed at $23^{\circ} \mathrm{C}$ in single lap shear up to $1 \%$ shear strain).

demonstrated an initial linear elastic behavior of solder with an initial tangent Young's modulus of $46 \pm 4 \mathrm{GPa}$ up to an apparent yield stress of $21 \pm 3 \mathrm{MPa}(0.2 \%$ offset $)$ in all the ageing states. After the initial macroscopic yield, the joints showed different strain hardening behaviors related to their ageing conditions. Although the as-soldered joints exhibited a considerable initial hardening, the hardening gradually decreased with ageing. In all ageing states, the hardening modulus decreased when increasing the applied strain, so that the stress level eventually saturated at around $3 \%$ of total strain. Considering yield stress at $3 \%$ total strain as a comparative measure of ultimate strength, it can be concluded that isothermal ageing for $144 \mathrm{~h}$ at $150{ }^{\circ} \mathrm{C}$ induced a severe $20 \%$ reduction in the ultimate strength of the solder joint (from $49 \pm 2$ to $38 \pm 4 \mathrm{MPa}$ ), while further ageing up to
296 h caused considerably less strength degradation $(\sim 5 \%)$.

For the sake of completeness, the high stress creep response of the solder was also investigated in a small series of steady state shear creep tests performed at $23{ }^{\circ} \mathrm{C}$ for both as-soldered and $144 \mathrm{~h}$ ageing states. The corresponding equivalent stress-strain rate results are presented in Fig. 11b. As the results mostly covered the high stress regime of the solder, it was thus fitted using a single power law term. Comparing the creep response of the $144 \mathrm{~h}$ aged state to the as-soldered condition, it can be observed that both creep stress exponents were found to be very similar at $\sim 12.8$ which is in close agreement with. ${ }^{42}$ However, the creep strain rate factor of $144 \mathrm{~h}$ aged specimens were observed to be about 37 times higher $\left(1.5 \times 10^{-23}\right.$ vs $\left.4 \times 10^{-25}\right)$ than that of the as-soldered joints. Interestingly, writing the creep power law in the form $\dot{\varepsilon}=A^{\prime}\left(\sigma / \sigma_{0}\right)^{n}$ with $\sigma_{0}$ equal to the equivalent yield stress at $1 \%$ strain obtained from the constant rate shear tests $\left(\sigma_{0}=44 \mathrm{MPa}\right.$ and $\sigma_{0}=33 \mathrm{MPa}$ for as soldered and $144 \mathrm{~h}$ aged state, respectively), leads to a nearly common value of creep factor $A^{\prime} \cong 1.4 \times 10^{-44}$. This could suggest that the change of creep behavior of the solder might be related to a shift in yield strength caused by a change in strengthening mechanisms such as particledislocation interactions (i.e. back stress) for example as discussed in ${ }^{14}$ or. $^{43}$

A specific experiment was also carried out to verify that the measured solder joint responses were not affected by localization and grain boundary sliding meaning that the obtained stress-strain responses truly reflect the continuum properties of the phases of the solder. As reported in the literature, localization and grain boundary sliding phenomena depend on several parameters like test temperature and loading rate as well as stress level, and is too complex to be accounted for in a comprehensive manner. ${ }^{7,8,23,28,42}$ To qualitatively examine the dominant mechanisms, a grid pattern was inscribed on the polished surface of specific SAC405 shear samples, as shown in Fig. 12a. The parallel lines were generated precisely by FIB milling with a distance of $130 \mu \mathrm{m}$. The width and depth of the lines were selected to be $\sim 800$ and $\sim 400 \mathrm{~nm}$, respectively, to be easily visible before and after testing without creating extensive damage. The grid lines over the sample surface obviously cross several grain boundaries as a shear sample typically contains more than 20 grains (see the EBSD maps in Fig. 10). Thus, if GBS occurred during shear deformation, a discontinuity or sharp jump in the lines at the intersections with grain boundaries should be visible. The specimens were subjected to the same shear test condition as described previously, but the test was interrupted after 4 and $12 \%$ of engineering shear strains for examination under SEM. Typical SEM micrographs of a typical zone on the sample surface after 4 and $12 \%$ of shear strain are shown in Fig. $12 \mathrm{~b}$ and c, 
(a)

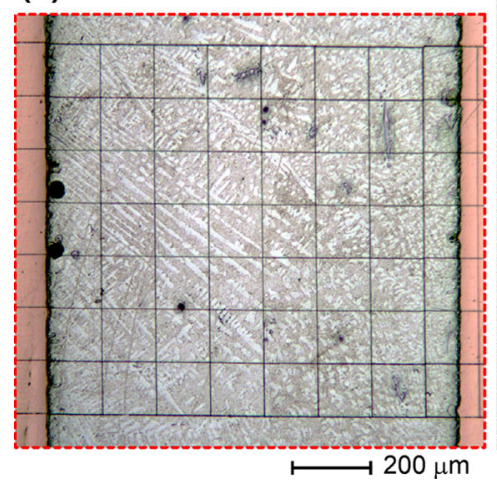

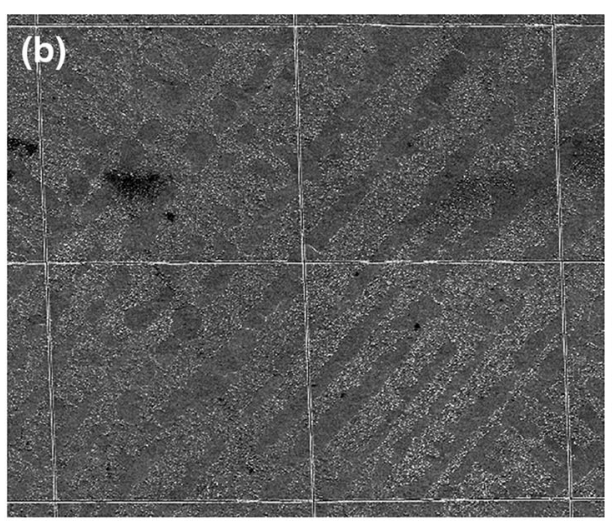

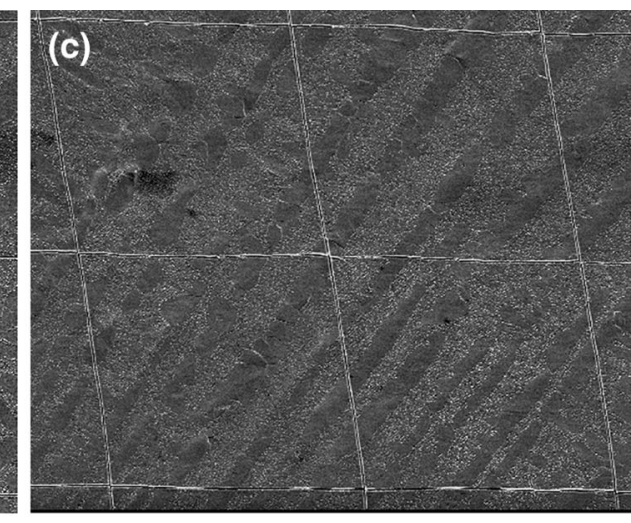

Fig. 12. (a) Grid on the surface of shear solder sample generated by FIB milling; SEM micrographs of a typical zone after (b) $4 \%$ and (c) $12 \%$ of shear strain.

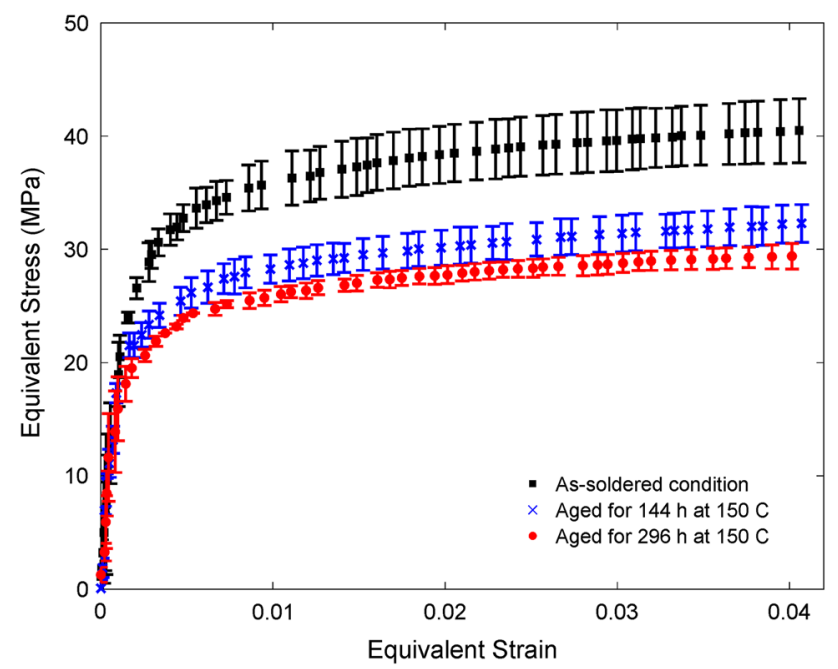

Fig. 13. Mises equivalent stress-strain response of $\beta$-tin at different ageing conditions at $0.24 \% / s$ equivalent strain rate.

respectively. Examination of the grid lines in deformed states shows that overall the lines remain continuous and without any local jump at different locations over the sample even after $12 \%$ of shear strain, demonstrating that the amount of GBS is insignificant. The change in the orientation of the lines was observed to be consistent with the amount of average shear strain. Moreover, the results showed a smooth strain distribution and deformation of the microstructures even at relatively high strain value with only very limited strain localization in a few areas after $12 \%$ of external strain. The limited localization at room temperature can be attributed to the relatively high strain rate used as well as to the presence of large grains and/or pinning effect of IMCs precipitated at grain boundaries. Accordingly, it can be concluded that the shear test employed in this study and the results in Fig. 11 are representative of the average continuum deformation behavior of SAC solder in the considered strain range and at room temperature.

\section{Quantitative Analysis of the IMCs Strengthening Effects}

In order to identify the strengthening effect of the IMCs in the SAC solder, sufficient insight on in situ deformation behavior of the $\beta$-tin matrix is of prime importance. The $\beta$-tin, by itself, is a complex anisotropic crystalline material whose behavior depends on several microstructural parameters like the size and orientation of its grains. ${ }^{44-46}$ Although significant data have been reported on pure $\beta$-tin behavior, for consistency with the rest of the present study, its average isotropic elasto-plastic response and grain structure at different ageing conditions were evaluated by adopting similar experimental methods as used in the case of SAC405 solder joints. For this purpose, $\beta$-tin shear joints were fabricated with an analogous reflow procedure using a pure tin paste containing tin powder and a flux similar to that of the solder paste. Due to the higher melting temperature of pure Sn compared to SAC405 alloy, the peak temperature in the reflow profile was selected to be $255^{\circ} \mathrm{C}$ to ensure enough dwelling time in the liquid state. The results in Fig. 13 represent the deformation behaviors of tin joints in the three selected ageing conditions, identified by shear tests at the same displacement rate as used for SAC solder. Similarly, the EBSD orientation map of the tin joint in as-soldered condition and after 144 and $296 \mathrm{~h}$ of ageing at $150{ }^{\circ} \mathrm{C}$ are shown in Fig. 14 .

Comparison of the stress-strain responses in Fig. 13 shows a considerable decrease in the yield strength of tin after annealing. Thus, the ultimate stress in the as-soldered tin joint was identified to be $\sim 30 \%$ higher than that after $296 \mathrm{~h}$ of ageing at $150{ }^{\circ} \mathrm{C}$. The orientation map in Fig. 14a indicates that the microstructure of the as-soldered tin joint, in contrast to SAC405 solder, consists of small grains with a typical size of $\sim 10 \mu \mathrm{m}$. Although the grain structure of the SAC solder joint was stable during ageing, an extensive evolution in the grain size in tin joints was observed. Indeed, ageing for $296 \mathrm{~h}$ at $150{ }^{\circ} \mathrm{C}$ caused a significant grain growth 

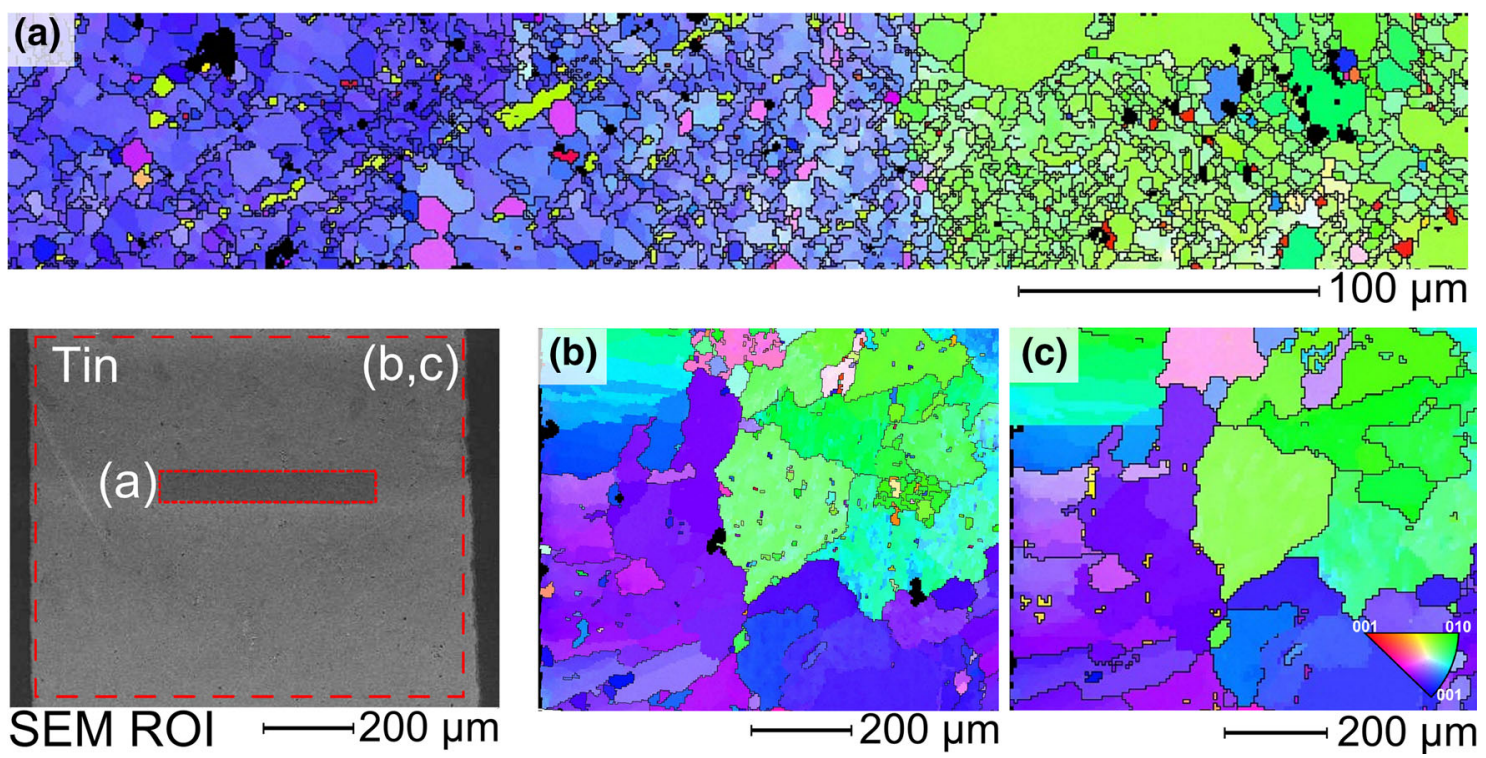

Fig. 14. Orientation map of $\beta$-tin in (a) as-soldered condition and after (b) $144 \mathrm{~h}$ and (c) $296 \mathrm{~h}$ at $150{ }^{\circ} \mathrm{C}$, indicating a considerable grain growth during annealing.

(a)

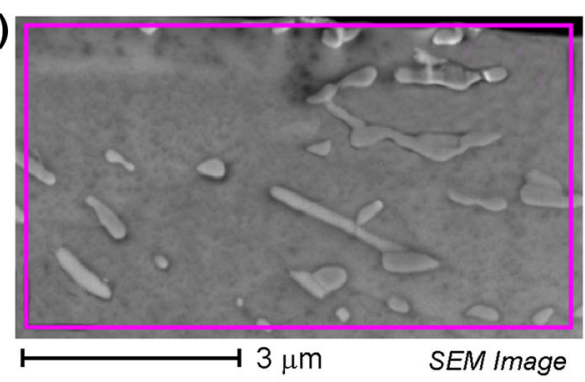

(c)

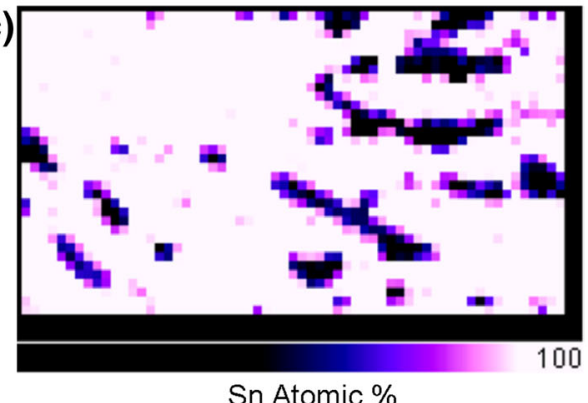

(b)

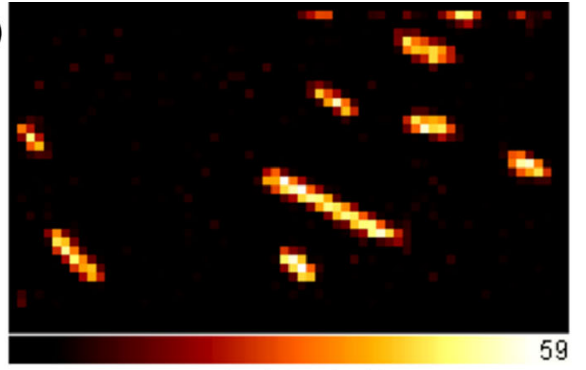

Cu Atomic \%

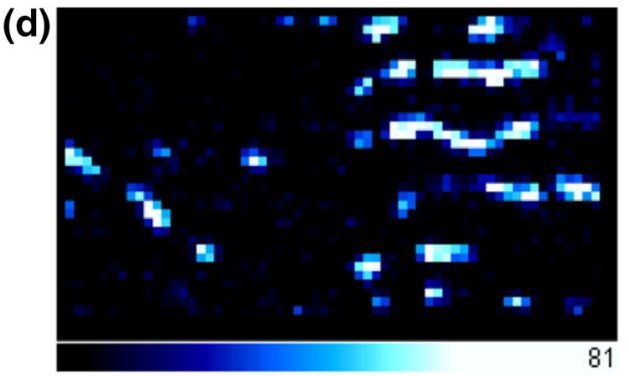

Ag Atomic \%

Fig. 15. Atomic percentage of elements in a selected zone of eutectic mixture of SAC solder joint in as-soldered condition: (a) SEM image, (b) $\mathrm{Cu}$, (c) Sn, (d) Ag.

up to a characteristic size of $\sim 200 \mu \mathrm{m}$, similar to that observed in SAC405 solder. Telang et al. ${ }^{7}$ have previously observed a similar grain evolution in polycrystalline tin and attributed it to the tendency of tin grains to reach lower boundary energy with coincident site lattices. On this basis, the higher deformation resistance of the as-soldered tin joint compared to the aged tin samples, observed in Fig. 13, can be attributed to an initial grain boundary strengthening effect (Hall-Petch strengthening) which becomes negligible after ageing due to a significant decrease in the grain boundary density. Hence, the deformation behavior of tin aged for $296 \mathrm{~h}$ at $150{ }^{\circ} \mathrm{C}$ can be considered as a good estimation of the $\beta$-tin behavior in SAC solder as it exhibits a similar grain size. However, it could be argued that the composition and consequently mechanical behavior of eutectic $\beta$-tin matrix in the SAC solder could be different from that of pure $\beta$-tin due to the potential presence of solute atoms in the alloying state and the corresponding solid solution strengthening. To verify this, the atomic distribution 
of elements in the eutectic phase of the as-reflowed SAC405 solder was examined in a high resolution EDX analysis. The maps in Fig. 15 represent the concentration of $\mathrm{Cu}, \mathrm{Ag}$, and $\mathrm{Sn}$ in the selected zone of the eutectic phase (shown in Fig. 15a) in the assoldered state. Although EDX is not a perfect tool for this kind of analysis, when the amount of solute atoms is not negligible, they can be easily observed in the high resolution EDX map. The atomic map in Fig. 15c shows the presence of only a few colored spots which indicates that almost all the matrix is made of tin (low concentration of solute atoms). Moreover, the $\mathrm{Sn}-\mathrm{Ag}-\mathrm{Cu}$ ternary phase diagram ${ }^{38}$ shows a negligible concentration of $\mathrm{Ag}$ and $\mathrm{Cu}$ in the eutectic tin of the SAC405 system at room temperature, which is also supported by the measured volume fraction and mass balance analysis shown previously. Hence, it can be reasonably concluded that, due to the negligible solubility of $\mathrm{Ag}$ and $\mathrm{Cu}$ atoms in the Sn matrix, solid solution strengthening effects can be considered negligible. As a result, the measured mechanical response of tin aged for $296 \mathrm{~h}$ at $150{ }^{\circ} \mathrm{C}$ was chosen as an estimate of the behavior of $\beta$-tin in SAC solder as it exhibits a similar grain structure and composition. However, it should be noted here that the yield stress and hardening of $\beta$ tin determined from shear tests in the present work differ significantly from the $\beta$-tin behavior previously measured by the authors in $^{24}$ using indentation in eutectic SAC405. The reason for this difference is mainly attributed to the much higher effective strain rate found when performing indentation tests with a Berkovitch tip. Moreover, the presence of higher initial density of dislocation caused by the presence of particles when testing $\beta$ tin in situ in the eutectic mixture is also a potential cause for this difference.

The measured stress-strain behavior of SAC solder for different ageing conditions are compared to unreinforced tin (aged for $296 \mathrm{~h}$ ) in Fig. 16. Noticeably higher yield strength of SAC solder joint can be observed in all the conditions compared to the unreinforced matrix. The ultimate yield strength of solder in the as-soldered condition and after 144 and $296 \mathrm{~h}$ of ageing were identified to be $20 \mathrm{MPa}(\sim 66 \%), 8 \mathrm{MPa}(\sim 26 \%)$ and $6 \mathrm{MPa}$ $(\sim 20 \%)$ higher than that of pure tin which can be attributed to the strengthening effect of the hard intermetallics in the SAC solder joints. Since the overall volume fraction of the IMCs remains constant during ageing, the change in their strengthening behavior must be mainly related to the identified changes of their morphology and spatial distribution.

\section{GENERAL DISCUSSION AND OUTLOOK}

Overall, the experimental results presented in this study tend to demonstrate that the considerable microstructure changes observed during isothermal ageing at $150{ }^{\circ} \mathrm{C}$ are responsible for a $\sim 70 \%$

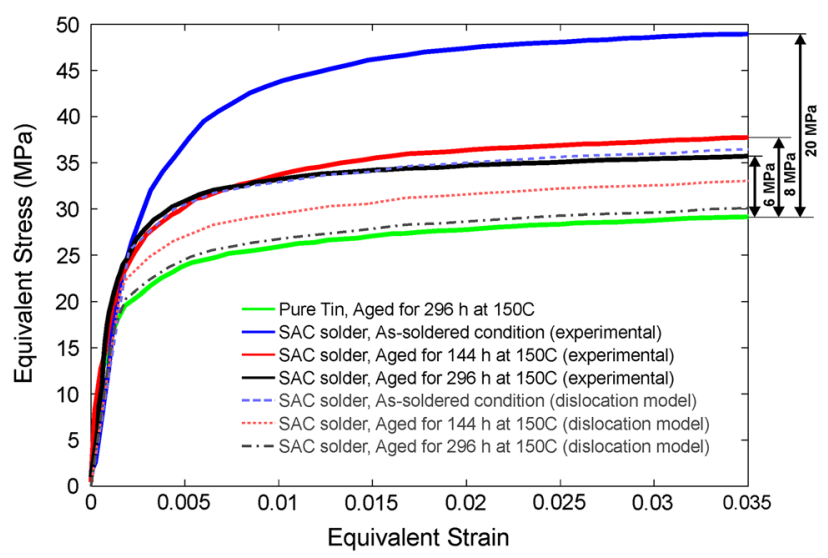

Fig. 16. Measured and simulated macroscopic response of SAC405 solder compared to that of pure $\beta$-tin and estimation of strengthening effect due to IMCs.

decrease in the strengthening effect of the IMCs and lead to a $\sim 25 \%$ reduction in ultimate strength of aged SAC405 solder. An analytical dislocation detachment model has been suggested in the literature to describe the evolution of the macroscopic mechanical response of SAC solder as a function of its microstructural features. ${ }^{5,23,42}$ According to this theory, the dislocations which climbed over the IMCs remain attracted by the particles and the enhanced strength of the solder mainly represent the back stress required to cause detachment of the dislocation segment from the particle. Accordingly, the yield strength of the eutectic mixture, $\sigma_{\text {Eut. }}$, can be estimated by:

$$
\sigma_{\text {Eut. }}=\sigma_{\text {Sn }}+\sigma_{\text {de }}
$$

where $\sigma_{\mathrm{Sn}}$ is the yield strength of the tin matrix and $\sigma_{\mathrm{de}}$ is the yield strength enhancement due to the dislocation detachment which can be calculated by: ${ }^{47}$

$$
\sigma_{\mathrm{de}}=\sigma_{\mathrm{Or}} \sqrt{1-K_{\mathrm{r}}^{2}}
$$

where $K_{\mathrm{r}}$ is relaxation factor $\left(=0.87^{8,48}\right)$ and $\sigma_{\mathrm{Or}}$ is the Orowan stress defined as:

$$
\sigma_{\mathrm{Or}}=\frac{0.4 \mathrm{MGb}}{\pi \lambda} \times \frac{\ln \left(D_{\mathrm{ave}} / b\right)}{(1-v)^{1 / 2}},
$$

where $M$ is the Taylor factor ( $=3$ ), $b$ is the Burger's vector $(=0.21 \mathrm{~nm}),{ }^{\S \$ 8} v$ is the Poisson ratio $(=0.34)$, and $G$ is the shear modulus (=19.7 GPa). ${ }^{8,48,49}$ Once the yield strength of the eutectic mixture is determined, the macroscopic yield strength of the solder, $\sigma_{\mathrm{SAC}}$, can be estimated using a rule of mixture over the meso-scale microstructures assuming that the

\footnotetext{
${ }^{\S}$ It should be noted that using other values for Burger's vector $b$ such as for example $b=0.317 \mathrm{~nm}$ as proposed in ${ }^{9}$ would not alter the following conclusions.
} 
dendrites and the eutectic phase work in parallel (upper bound estimate):

$$
\sigma_{\mathrm{SAC}}=F_{\text {Eut. }} \sigma_{\text {Eut. }}+\left(1-F_{\text {Eut. }}\right) \sigma_{\mathrm{Sn}} .
$$

Using the morphometrics of the IMCs obtained from geometrical analyses, namely $D_{\text {ave }}$ and $\lambda$, in Eqs. 5-8, the deformation behaviors of SAC405 solder in the three considered ageing states were estimated and are shown by dashed lines in Fig. 16. The results indicate that the dislocation detachment theory qualitatively represents the reducing trend in the IMCs strengthening effect during ageing as the decrease in the particle-dislocation interaction due to an increase in the inter-particle spacing and particle size can be reasonably captured in the model. However, comparison of the modeling and experimental data in Fig. 16 shows that the dislocation detachment model considerably underestimates the amount of the strength enhancement caused by the IMCs (20-80\% underestimation depending on the ageing condition). According to the considerable knowledge in the field of particlereinforced metal matrix composites (PMMCs), when the characteristic size of the particles and interaction distance becomes very small $(<1 \mu \mathrm{m})$, in addition to the back stress caused by dislocationprecipitates interaction, particle size effect driven by the increase in density of geometrically necessary dislocations (GNDs) in the matrix may become important. Also, when the volume fraction of the hard particles is relatively important (more than 1-2 \%), the composite load-sharing effect between the matrix and particles can also enhance the overall strength of the media. ${ }^{50-53}$ On this basis, the lower strengthening value predicted by the dislocation detachment model compared to the experiments could be attributed to additional strengthening mechanisms, such as those cited above, which may need to be considered to achieve quantitative predictions of the strength decrease with ageing. To understand the contribution of each strengthening mechanism on the overall behavior of the solder, a multi-scale computational homogenization model of SAC solder based on actual 3D microstructure data has been developed by the authors ${ }^{25}$ and will be the subject of a follow-up paper.

\section{SUMMARY AND CONCLUSIONS}

In this study, the microstructure evolution in SAC405 solder during isothermal ageing was visualized and analyzed for the first time in 3D using a combination of FIB/SEM and synchrotron $x$-ray tomography techniques. Using an optimized reflow profile with a cooling rate representative of industrial

\footnotetext{
"The SAC solder, due to high contrast in the mechanical properties of its constituents, can be seen as a PMMC in which hard intermetallic particles play the role of reinforcements and the tin plays the role of ductile matrix.
}

production, the microstructure of SAC405 in the assoldered state was found to be composed of $\sim 30 \mathrm{vol} \%$ of $\beta$-tin dendrites and $\sim 70 \mathrm{vol} \%$ of the eutectic phase, with occasionally some large leaf-shape $\mathrm{Ag}_{3} \mathrm{Sn}$ plates and long hollow $\mathrm{Cu}_{6} \mathrm{Sn}_{5}$ whiskers in about $10 \%$ of the samples. The eutectic phase in the as-soldered condition consisted of sub-micron needle-shape $\mathrm{Ag}_{3} \mathrm{Sn}$ and $\mathrm{Cu}_{6} \mathrm{Sn}_{5}$ intermetallics with a volume fraction of $8.6 \%$, an aspect ratio of $\sim 4$, mean diameter of $\sim 205 \mathrm{~nm}$, and inter-particle spacing of $\sim 630 \mathrm{~nm}$ which followed a preferred growth direction related to tin grain orientation. During isothermal ageing, the overall volume fraction of intermetallics in the solder joint was observed to remain nearly constant. However, strong evolutions were identified in their morphology and distribution. The 3D morphometrics analysis have shown a continuous growth of the IMCs particles to create fewer and larger precipitates by dissolution of the sub-micron particles present in the eutectic mixture (Ostwald ripening). Considerable decrease in the aspect-ratio of the IMCs remaining in the eutectic mixture and increase of interparticle distance was also observed. The driving force for those changes can obviously be attributed to the evolution of the system towards a lower total surface energy. The measured diffusion kinetics results showed a linear relationship

between the average volume of coarsened $\mathrm{Ag}_{3} \mathrm{Sn}$ and $\mathrm{Cu}_{6} \mathrm{Sn}_{5}$ particles and isothermal ageing time which confirmed that bulk diffusion was the main rate-controlling mechanism.

Moreover, the effect of isothermal ageing on the grain structure of SAC405 solder and $\beta$-tin were studied by EBSD analysis. The as-reflowed SAC solders exhibited a coarse grain structure ( $>200 \mu \mathrm{m}$, i.e., a few grains across the joint size), without any clear preferred orientation. Interestingly, this coarse grain structure remained stable during isothermal ageing at $150{ }^{\circ} \mathrm{C}$ up to the point where Sn dendrites could not be distinguished from ex-eutectic phases. On the contrary, in pure $\mathrm{Sn}$ joints, ageing caused a considerable grain growth starting from a fine grain structure of $\sim 10 \mu \mathrm{m}$ to reach about $\sim 200 \mu \mathrm{m}$ after ageing. Thus, the effect of ageing on the yield strength of pure $\beta$-tin joints can mostly be attributed to the decrease in the HallPetch effect due to grain growth and is obviously a different mechanism than that observed in SAC solders. However, as it presents a similar grain structure and composition, the mechanical properties of pure $\beta$-tin aged for $296 \mathrm{~h}$ at $150{ }^{\circ} \mathrm{C}$ was considered as a good estimate of the behavior of the $\mathrm{Sn}$ matrix in SAC solder, and was thus used as a reference to quantify the strengthening effects due to the presence of IMCs particles.

On the basis of single lap shear test results, it was observed that ageing was responsible for a significant decrease in the initial hardening and ultimate strength of the SAC405 solder, with a $\sim 20 \%$ reduction in the ultimate strength of the joint after ageing for 
$144 \mathrm{~h}$ at $150{ }^{\circ} \mathrm{C}$. However, due to strengthening effect of IMCs, the yield strength of SAC solders was shown to be noticeably higher than that of the unreinforced tin in all ageing conditions. The observed decrease in strengthening effect of the IMCs during ageing (from 20 to $6 \mathrm{MPa}$ ) was quantified by comparison with pure tin joints and attributed to the changes in the morphology of IMCs particles and increase in inter-particle spacing. Finally, it was shown that, although the dislocation detachment model was able to qualitatively represent the reducing trend in the IMCs strengthening effect during ageing, it considerably underestimated the amount of strength enhancement and could not quantitatively predict the magnitude of the ageing effects observed in the present work. More advanced models considering particle size effects and complex load-sharing interactions should thus be considered for better predictions.

\section{ACKNOWLEDGEMENTS}

This research work was supported by the Swiss Secretariat for Education and Research (SER Grant C08.0030) and was conducted in the framework of the European COST action MP 0602 HISOLD. The x-ray tomography tests were performed on the TOMCAT beamline at PSI, Switzerland. We are grateful to the staff of TOMCAT beam-line at SLSPSI, particularly Dr. Julie Fife, whose helps have made the tomographic analyses possible. The authors would like to thank the personnel of LSMX and CIME of EPFL, especially Prof. Michel Rappaz and Dr. Marco Cantoni, for their precious help in microstructure characterization.

\section{REFERENCES}

1. I.E. Anderson, J. Mater. Sci. Mater. Electron. 18, 55 (2007).

2. J.J. Sundelin, S.T. Nurmi, T.K. Lepisto, and E.O. Ristolainen, Mater. Sci. Eng. A 420, 55 (2006).

3. K.W. Moon and W.J. Boettinger, JOM 56, 22 (2004).

4. I. Ohnuma, M. Miyashita, K. Anzai, X.J. Liu, H. Ohtani, R. Kainuma, and K. Ishida, J. Electron. Mater. 29, 1137 (2000).

5. I. Dutta, C. Park, and S. Choi, Mater. Sci. Eng. A 379, 401(2004).

6. R.S. Sidhu, S.V. Madge, X. Deng, and N. Chawla, J. Electron. Mater. 36, 1615 (2007).

7. A.U. Telang, T.R. Bieler, J.P. Lucas, K.N. Subramanian, L.P. Lehman, Y. Xing, and E.J. Cotts, J. Electron. Mater. 33, $1412(2004)$.

8. J. Gong, C. Liu, P.P. Conway, and V.V. Silberschmidt, $M a-$ ter. Sci. Eng. A 427, 60 (2006).

9. M. Kerr and N. Chawla, Acta Mater. 52, 4527 (2004).

10. F. Ochoa, J.J. Williams, and N. Chawla, J. Electron. Mater. 32,1414 (2003).

11. S.L. Allen, M. Notis, R.R. Chromik, and R.P. Vinci, J. Mater. Res. 19, 1417 (2004).

12. A.R. Fix, W. Nuchter, and J. Wilde, Solder. Surf. Mt. Technol. 20, 13 (2008).

13. A.W. Gibson, S.L. Choi, K.N. Subramanian, and T.R. Bieler, TMS Annual Meeting Proceedings (1997), p. 97.

14. I. Dutta, P. Kumar, and G. Subbarayan, JOM 61, 29 (2009).

15. I. Dutta, D. Pan, R.A. Marks, and S.G. Jadhav, Mater. Sci. Eng. A 410-411, 48 (2005).

16. S. Wiese and K.J. Wolter, Microelectron. Reliab. 47, 223 (2007).

17. K. Jung and H. Conrad, J. Electron. Mater. 30, 1303 (2001).
18. R.S. Sidhu and N. Chawla, Mater. Charact. 52, 225 (2004).

19. R.S. Sidhu and N. Chawla, Scr. Mater. 54, 1627 (2006).

20. K.E. Yazzie, J.J. Williams, N.C. Phillips, F. De Carlo, and N. Chawla, Mater. Charact. 70, 33 (2012).

21. G. Cuddalorepatta and A. Dasgupta, Acta Mater. 58, 5989 (2010).

22. X. Deng, R.S. Sidhu, P. Johnson, and N. Chawla, Metall. Mater. Trans. A 36A, 55 (2005).

23. M.L. Huang, L. Wang, and C.M.L. Wu, J. Mater. Res. 17, 2897 (2002).

24. M. Maleki, J. Cugnoni, and J. Botsis, Acta Mater. 61, 103 (2013).

25. M. Maleki, Damage and Deformation in Lead-free Solder Joints (Ph.D. thesis, Ecole Polytechnique Fédérale de Lausanne EPFL, 2012). doi:10.5075/epfl-thesis-5565.

26. K.S. Kim, S.H. Huh, and K. Suganuma, Mater. Sci. Eng. A 333, 106 (2002).

27. M. Maleki, J. Cugnoni, and J. Botsis, J. Electron. Mater. 40, 2081 (2011).

28. F. Ochoa, X. Deng, and N. Chawla, J. Electron. Mater. 33, 1596 (2004).

29. H. Ma, J.C. Suhling, P. Lall, and M.J. Bozack, Proceedings of the 56th Electronic Components and Technology Conference, ECTC'06 (2006), pp. 849-864.

30. M.D. Uchic, L. Holzer, B.J. Inkson, E.L. Principe, and P. Munroe, MRS Bull. 32, 408 (2007).

31. F.A. Dilmanian, Z. Zhong, B. Ren, X.Y. Wu, L.D. Chapman, I. Orion, and W.C. Thomlinson, Phys. Med. Biol. 45, 933 (2000).

32. M. Rappaz, F. Kohler, J. Valloton, A.B. Phillion, and M. Stampanoni, Metall. Mater. Trans. A 41, 563 (2010).

33. M. Stampanoni, A. Groso, A. Isenegger, G. Mikuljan, Q. Chen, A. Bertrand, S. Henein, R. Betemps, U. Frommherz, P. Böhler, D. Meister, M. Lange, and R. Abela, in, 2006.

34. K.S. Kim, S.H. Huh, and K. Suganuma, J. Alloys Compd. 352, 226 (2003).

35. R.A. Gagliano and M.E. Fine, JOM 53, 33 (2001).

36. T. Laurila, V. Vuorinen, and J.K. Kivilahti, Mater. Sci. Eng. $R$ 49, 1 (2005).

37. W. Kurz and D.J. Fisher, Fundamentals of Solidification (Aedermansdorf: Trans Tech Publications, 1998).

38. S.W. Chen, C.H. Wang, S.K. Lin, and C.N. Chiu, J. Mater. Sci. Mater. Electron. 18, 19 (2007).

39. [39] www.metallurgy.nist.gov.

40. J. Gong, C. Liu, P.P. Conway, and V.V. Silberschmidt, Scr. Mater. 61, 682 (2009).

41. D.W. Henderson, J.J. Woods, T.A. Gosselin, J. Bartelo, D.E King, T.M. Korhonen, M.A. Korhonen, L.P. Lehman, E.J. Cotts, S.K. Kang, P. Lauro, D.Y. Shih, C. Goldsmith, and K.J. Puttlitz, J. Mater. Res. 19, 1608 (2004).

42. R.S. Sidhu, X. Deng, and N. Chawla, Metall. Mater. Trans. A 39, 349 (2008).

43. P. Kumar, Z. Huang, S. Chavali, D.K. Chan, I. Dutta, G. Subbarayan, and V. Gupta, IEEE Trans. Compon. Packag. Manuf. Technol. 2, 256 (2012).

44. R.J. McCabe and M.E. Fine, Metall. Mater. Trans. A 33, 1531 (2002).

45. F. Yang and J.C.M. Li, J. Mater. Sci. 18, 191 (2007)

46. M.D. Mathew, H. Yang, S. Movva, and K.L. Murty, Metall. Mater. Trans. A 36A, 99 (2005).

47. E. Arzt and D.S. Wilkinson, Acta Metall. 34, 1893 (1986)

48. Y.D. Han, H.Y. Jing, S.M.L. Nai, C.M. Tan, J. Wei, L.Y. Xu, and Zhang SR, J. Phys. D Appl. Phys. 42, 125411 (2009).

49. P.T. Vianco, J.A. Rejent, and A.C. Kilgo, J. Electron. Mater. 32, 142 (2003).

50. N. Chawla, R.S. Sidhu, and V.V. Ganesh, Acta Mater. 54, 1541 (2006).

51. M. Kouzeli and A. Mortensen, Acta Mater. 50, 39 (2002).

52. C.W. Nan and D.R. Clarke, Acta Mater. 44, 3801 (1996).

53. D.S. Wilkinson, E. Maire, and J.D. Embury, Mater. Sci. Eng. A 233, 145 (1997). 